\title{
Tratamento da Dermite Atópica Moderada a Grave em Adultos
}

\author{
Pedro Ponte \\ Serviço de Dermatologia, Hospital Lusíadas Lisboa, Portugal
}

RESUMO - A dermite atópica é uma doença cutânea inflamatória crónica, caracterizada por lesões eritemato-descamativas pruriginosas recorrentes, frequentemente associadas a sobreinfecção. É uma das mais comuns doenças cutâneas, afectando 10\% a $20 \%$ das crianças e $1 \%$ a $3 \%$ dos adultos, sendo uma causa significativa de morbilidade, compromisso de qualidade de vida e consumo de cuidados de saúde. Ainda que muitos doentes possam ser tratados de forma satisfatória com medicação tópica e fototerapia, um subgrupo de doentes requer terapêutica sistémica mais agressiva para controlar a inflamação cutânea, reduzir sintomas, prevenir exacerbações e melhorar a qualidade de vida. Para além disso, as formas graves da doença têm um profundo impacto na vida dos doentes o que requer a combinação de tratamentos tópicos e sistémicos para as controlar, depois de adequadamente excluídos os motivos para falência terapêutica. Apesar das múltiplas opções clássicas disponíveis, terapêuticas eficazes e seguras estão limitadas pela toxicidade cumulativa e efeitos adversos associados. Este artigo revê o uso e a evidência científica disponível destas opções de tratamento na dermite atópica moderada a grave do adulto, bem como vários novos e promissores fármacos presentemente em investigação.

PALAVRAS-CHAVE - Adulto; Anticorpos Monoclonais; Dermatite Atópica/tratamento; Eczema; Fototerapia.

\section{Management of Moderate to Severe Atopic Dermatitis in Adults}

ABSTRACT - Atopic dermatitis is a chronic inflammatory skin condition characterized by relapsing pruritic, scaly, erythematous papules and plaques frequently associated with superinfection. It is one of the most common skin diseases affecting $10 \%-20 \%$ of children and 1\%-3\% of adults, and it is a significant cause of morbidity, quality-of-life impairment and health-care costs. Although many patients can be treated satisfactorily with topical medications and phototherapy, a smaller subset requires more aggressive systemic therapies to control skin inflammation, reduce symptoms, prevent flares, and improve quality of life. Besides, severe atopic dermatitis has a profound effect on many aspects of the patient's life, and a combination of topical and systemic treatment is often required to control the disease, after ensuring all treatment failure causes are adequately excluded. Despite the available classical options, effective and safe treatments for patients with moderate-to-severe atopic dermatitis are limited due to toxicity and side effects. This article reviews the use and the scientific evidence of these medications in the treatment of adult moderate to severe atopic dermatitis, as well as several promising targeted therapies currently in development.

KEYWORDS - Adult; Antibodies, Monoclona; Dermatitis, Atopic/drug therapy; Dermatitis, Atopic/therapy; Eczema; Phototherapy.

\section{INTRODUÇÃO}

A dermite atópica (DA) é uma doença cutânea inflamatória crónica, geneticamente determinada, que afecta $10 \%$ a $20 \%$ das crianças e $1 \%$ a $3 \%$ dos adultos que vivem em países industrializados. ${ }^{1,2}$ É uma das mais comuns doenças cutâneas e tem um custo económico individual e global elevado..$^{3,4}$ Ainda assim, a DA é encarada pela comunidade médica e pela sociedade como uma doença menor. ${ }^{5}$ Embora a maioria dos casos seja ligeiro em termos de actividade clínica, esta doença interfere negativamente no quotidiano

Por decisão do autor, este artigo não foi redigido de acordo com os termos no novo Acordo Ortográfico

Correspondência: Pedro Ponte

Serviço de Dermatologia - Hospital Lusíadas Lisboa, Portugal

Rua Abílio Mendes

1500-458 Lisboa, Portugal

E-mail: pedrofponte@gmail.com

DOI: https://dx.doi.org/10.29021/spdv.76.4.958
Recebido/Received

13 Junho/June 2018

Aceite/Accepted

28 Setembro/September 2018 


\section{Educação Médica Contínua}

da generalidade dos doentes $s^{6,7}$ tendo, em subpopulações de adultos seleccionadas, um impacto na qualidade de vida superior ao de outras doenças cutâneas comuns como a psoríase. ${ }^{8}$ Tem igualmente um efeito negativo superior na saúde mental quando comparado com outras doenças crónicas como a diabetes e a hipertensão. ${ }^{9}$

\section{DERMITE ATÓPICA GRAVE}

A maioria dos doentes com DA tem doença ligeira a moderada; contudo, uma subpopulação desenvolve sintomas graves. ${ }^{10}$ Estima-se que $10 \%$ a $20 \%$ dos doentes sofram de doença grave e esta percentagem parece ser maior em adultos. "Vários estudos têm utilizado escalas para determinar a gravidade da DA, sendo o Severity Scoring of Atopic Dermatitis (SCORAD) index, o Eczema Area and Severity Index (EASI) e o Investigator Global Assessment (IGA) scale os mais habitualmente utilizados e validados. ${ }^{12}$ EASI superior a 6 (escala de 0 a 72), SCORAD superior a 24 (escala de 0 a 103) e IGA superior a 3 (escala de 0 a 5) correspondem a doença moderada a grave, sendo que o EASI se assumiu como o índice preferencial na determinação da gravidade da DA em ensaios clínicos. ${ }^{13}$ Ainda que estas escalas sejam úteis para homogeneização de resultados nesses ensaios, não são habitualmente utilizadas na prática clínica. Do ponto de vista prático, doentes com DA extensa que não respondam à terapêutica convencional podem ser classificados como tendo DA grave refractária. ${ }^{14} \mathrm{~A}$ DA grave pode ser caracterizada pela presença de lesões cutâneas muito disseminadas ou generalizadas, ou pelo impacto que as lesões possam ter na qualidade de vida do ponto de vista físico ou psicológico.

\section{ABORDAGEM TERAPÊUTICA}

Estão disponíveis múltiplas terapêuticas para o tratamento da DA grave. Contudo, dada a natureza crónica e genética da doença, não há cura para a $\mathrm{DA} e$, por isso, a terapêutica corrente é focada na evicção e controlo de factores agravantes específicos e não específicos, na hidratação cutânea e na redução da inflamação. ${ }^{15}$ De facto, o uso de corticosteróides e inibidores da calcineurina tópicos para o controlo da inflamação, em conjugação com emolientes para optimizar a função barreira, constituem os pilares da terapêutica. E ainda que estas medidas ofereçam um rápido e efectivo controlo na doença ligeira a moderada, é muitas vezes necessário recorrer a opções de segunda linha, como a fototerapia e a terapêutica sistémica imunossupressora, nas situações graves e refractárias. ${ }^{15,16} \mathrm{~A}$ evidência da eficácia e segurança destas modalidades terapêuticas em crianças é limitada e está fora do âmbito desta revisão. Tal como em adultos, deve recorrer-se a elas em situações em que todas as opções tenham falhado ou em que a doença tenha um significativo impacto na qualidade de vida. ${ }^{17}$

\section{Motivos para falência terapêutica}

Antes de iniciar tratamentos de segunda linha, deve ser garantido que a doença refractária não é o resultado da presença de factores exacerbantes evitáveis ou reversíveis ${ }^{18}$ ou de um diagnóstico incorrecto.

\section{Desencadeantes ambientais}

Os estímulos ambientais são uma das principais causas das exacerbações da DA e a sua evicção é uma importante forma de ajudar a controlar a actividade da doença. ${ }^{19}$ Podem incluir alterações de temperatura, ambientes com baixa humidade, stress emocional ou a exposição a agentes irritativos, como detergentes ou agentes de lavagem inapropriados. ${ }^{18}$ Além da redução das crises, a evicção destes estímulos bem como a optimização dos cuidados de higiene e uso de emolientes adequados poderão desempenhar um importante papel na gestão da doença a longo prazo.

\section{Infecções}

Doentes com DA têm um risco acrescido de infecção secundária bacteriana, viral ou fúngica. Esta possibilidade deve ser considerada em doentes cujas lesões aparentem ser refractárias à terapêutica convencional.

A colonização por Staphylococcus aureus ocorre mais frequentemente em indivíduos com DA do que na restante população. ${ }^{20} \mathrm{~A}$ infecção por este agente, particularmente quando há expressão de exotoxinas, é uma causa conhecida de agravamento da DA. ${ }^{20}$ Estão disponíveis cada vez mais estudos que correlacionam a actividade e constituição do microbioma cutâneo com o desencadeamento, gravidade e manutenção da dermatose. ${ }^{21}$ Os Streptococci do Grupo A são desencadeantes menos comuns. ${ }^{22} \mathrm{~A}$ presença de lesões exsudativas com crosta melicérica, a distribuição assimétrica e a extensão progressiva são sinais evocativos desta intercorrência.

A infecção por HSV também pode ocorrer e a sua disseminação constitui uma emergência dermatológica que requer a instituição rápida de terapêutica antiviral sistémica. ${ }^{23}$ O desenvolvimento de vesículas ou pústulas monomórficas sobre as áreas eczematizadas, com ou sem sintomas constitucionais, sugere o diagnóstico.

\section{Hipersensibilidade a produtos usados no tra- tamento \\ O defeito de barreira cutânea na DA está associado a} uma maior permeabilidade a agressões externas. Esta alteração poderia estar associada a um maior risco de sensibilização por agentes tópicos, sobretudo devido ao maior consumo de emolientes e medicamentos tópicos. Todavia, estudos epidemiológicos não revelaram um risco superior de dermite de contacto alérgica (DCA) em doentes com DA quando comparados com a população geral. ${ }^{24,25}$ Mesmo assim, as reacções de hipersensibilidade retardada a emolientes tópicos e a medicamentos deverão ser consideradas quando existe má resposta à terapêutica ou agravamento da doença com a sua aplicação.

A DCA poderá ser causada por veículos ou por ingredientes activos de emolientes (como a lanolina, propilenoglicol, 


\section{Educação Médica Contínua}

etilenodiamina, formaldeído), por medicamentos anti-inflamatórios ou imunomoduladores (dermocorticóides, inibidores da calcineurina) e por antibióticos tópicos (bacitracina, neomicina). ${ }^{26-28}$ Alguns autores recomendam a inclusão de agentes antissépticos e da série de emolientes nos testes epicutâneos a realizar em doentes com DA. ${ }^{28} \mathrm{~A}$ identificação e eliminação do alergénio pode conduzir a melhoria clínica significativa.

\section{Alergias alimentares e ambientais}

O mecanismo fisiopatológico da DA não assenta na hipersensibilidade de tipo 1, nem está necessariamente associado a sensibilização alérgica. Contudo, existe alguma evidência que suporta o papel de reacções alérgicas do tipo I nalguns doentes. Até cerca de $80 \%$ de crianças com DA desenvolvem asma e / ou rinite alérgica durante a infância e adolescentes com asma têm mais frequentemente DA do que adolescentes sem asma. ${ }^{29,30}$

Múltiplos estudos demonstram um aumento das taxas de sensibilização a aeroalergénios e a alimentos em doentes com DA, em média $50 \%$ de crianças e $35 \%$ de adultos, ainda que estes valores variem muito entre estudos. ${ }^{30,31}$ Mas a evidência de sensibilização alergénica não é prova de alergia clinicamente relevante. A confirmação clínica é particularmente importante quando existe suspeita de alergia alimentar, uma vez que a evicção de certos alimentos poderá resultar num risco nutricional desnecessário.

Foi reportado que as exacerbações da DA induzidas por alimentos ocorrem em até $10 \%$ das crianças e que são incomuns em adultos. ${ }^{32} \mathrm{O}$ diagnóstico não é linear porque pode ocorrer agravamento induzido por um alimento apesar da quantificação serológica de $\lg E$ específica e a dos testes cutâneos por picada (testes prick) serem negativos. Falsos positivos são também comuns na medida em que estes doentes têm habitualmente elevados níveis de lgE total. ${ }^{33}$

O diagnóstico de exacerbação da DA induzida por alimentos assenta num período de exclusão dietética do alimento suspeito para confirmar que a doença cutânea melhora, ${ }^{34}$ sendo que apenas os doentes que agravam com alimentos específicos beneficiem dessa prova. Esse período poderá durar 4 semanas, momento em que a intervenção é avaliada. Muitas crianças deixarão de ter exacerbações relacionadas com alimentos à medida que crescem, pelo que a reavaliação destes factores desencadeantes é requerida com intervalos de 6 a 12 meses. ${ }^{14,34}$ Uma revisão Cochrane concluiu que poderá haver algum benefício numa dieta sem ovos em crianças com suspeita de alergia a ovos com $\lg \mathrm{E}$ específica positiva, mas não encontrou benefício na evicção de leite e ovos, ou em dietas restritivas em doentes com DA não seleccionados. ${ }^{35}$

Alguns aeroalergénios foram apontados como desencadeantes de surtos de DA. ${ }^{36}$ Contudo, as determinações de $\lg$ E específicas e os testes cutâneos por picada não podem ser utilizados para estudar reacções de hipersensibilidade retardada a esses agentes. As medidas gerais para controlo de ácaros do pó, pólenes ou pelos de animais poderão ser consideradas, particularmente em doentes com asma ou rinite alérgica despoletada por esses alergénios. Não está provado que essas intervenções tenham qualquer benefício no controlo da doença cutânea. ${ }^{37}$

\section{Baixa adesão terapêutica}

A adesão à terapêutica tópica é muito baixa em doentes com DA. Mais de $50 \%$ não realiza os tratamentos adequadamente. ${ }^{38}$ Os motivos incluem a preocupação sobre os efeitos secundários da medicação, a cosmeticidade dos produtos tópicos e o insuficiente tempo despendido na educação dos doentes e dos cuidadores acerca da sua correcta utilização ${ }^{39}$ (Tabela 1).

\section{Diagnóstico incorrecto}

O diagnóstico de DA é habitualmente simples para um dermatologista mas poderá ser mais desafiante em doentes tratados por médicos de outras especialidades. ${ }^{40}$ Podem

\section{Tabela 1 - Motivos para não adesão terapêutica.}

\section{MEDICAÇÃO DISPONÍVEL MAS NÃO USADA / USADA INCORRECTAMENTE}

- Instruções inadequadas

- Posologia complexa

- Percepção que o tratamento é ineficaz

- Percepção / receio de efeitos secundários não toleráveis

- Tratamento delegado em crianças demasiado novas para o fazer eficazmente

- Percepção que o tratamento é cosmeticamente inadequado

- Tratamento agrava a DA

- Medicação provoca dor ou ardor

- Medicação termina mas o doente não recorre ao médico para mais prescrições

- Medicação não disponível na farmácia

- Medicação demasiado dispendiosa

- Médico prescreve quantidade inadequada 


\section{Educação Médica Contínua}

colocar-se diagnósticos diferenciais com dermatoses primárias, imunodeficiências, toxidermias, doenças metabólicas, infecciosas e neoplásicas (Tabela 2). ${ }^{14}$ Lesões atípicas na sua distribuição, ausência de prurido ou a falta de resposta aos tratamentos tópicos, doentes com antecedentes pessoais de infecções sistémicas ou sintomas gastrintestinais, e doentes com antecedentes familiares atípicos deverão motivar a procura de diagnósticos alternativos. $O$ diagnóstico de DA é baseado nos critérios de Hanifin e Rajka ${ }^{41}$ ou nas modificações mais recentes adaptadas pela British Association of Dermatologists ${ }^{42}$ e pela conferência de consenso sobre DA da American Academy of Dermatology. ${ }^{43}$

\section{Tabela 2 - Diagnósticos diferenciais de dermite} atópica.

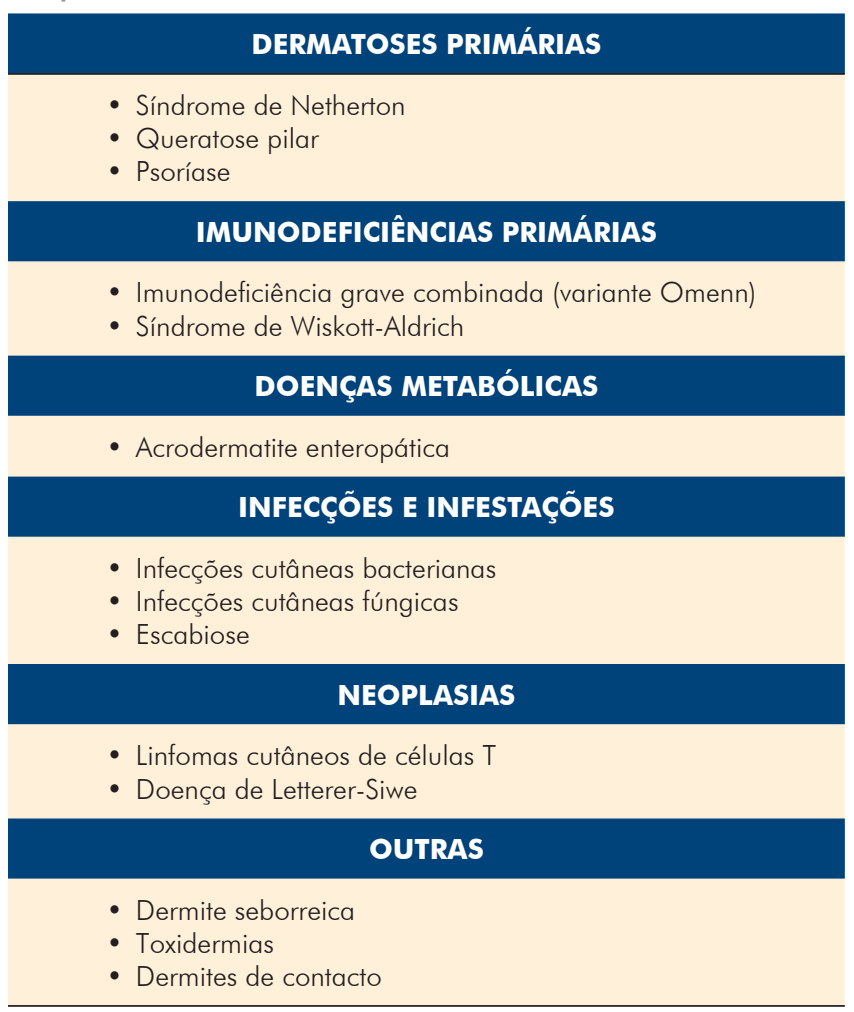

\section{Fototerapia}

A radiação ultravioleta (UV) é uma opção terapêutica para adolescentes e adultos com DA grave mas implica experiência do clínico e do pessoal de apoio para que seja segura e eficaz. Inclui:

- UVB de banda estreita (nbUVB) - limita o espectro de emissão UVB no comprimento de onda em redor de $311 \mathrm{~nm}$

- UVA1 - limita o especto de emissão de UVA aos comprimentos de onda mais longos (340-400 nm), o que permite uma penetração mais profunda do que comprimentos mais curtos

- Fotoquimioterapia com psoraleno + UVA (PUVA)
- implica a administração de um agente fotossensibilizante antes da exposição a UVA de banda larga

- Combinação de UVA + UVB de banda larga (UVAB)

Existem poucos estudos que comparem as diferentes modalidades de fototerapia e os existentes envolvem amostras pequenas com doses de radiação muito variáveis. Se disponível, a preferência poderá ser dada a UVAl para agudizações da doença, e a nbUVB para a doença refractária crónica da maioria dos doentes. ${ }^{44}$

A incidência de eventos adversos é desconhecida mas é extrapolável dos trabalhos com psoríase. Os mais comuns incluem dano actínico, eritema, prurido, dor e ardor locais; os menos comuns incluem lentigos, reacções de fotossensibilidade, foliculite, foto-onicólise, reactivação do vírus do herpes simples, hipertricose facial e cancro cutâneo não melanoma. ${ }^{45}$ As diferentes modalidades de fototerapia têm perfis distintos de segurança.

\section{1. nbUVB}

A nbUVB é efectiva no tratamento de DA moderada a grave, sendo bem tolerada e segura. Num ensaio controlado e randomizado, atingiu o dobro da redução da actividade da doença quando comparado com UVA de banda larga ao fim de 24 sessões, verificando-se uma redução da extensão da doença em $6,7 \%$ contra $-1,0 \%$, respectivamente. ${ }^{46}$ Mais recentemente, num estudo observacional prospectivo, a comparação entre nbUVB e nbUVB + UVA de banda larga não demonstrou diferenças nas taxas de repostas completas entre os 2 grupos. A duração de resposta foi significativamente mais longa no grupo nbUVB $(10,1$ vs 6,8 meses). ${ }^{47}$ Quando comparado com UVA + UVB de banda larga, a nbUVB demonstrou uma significativa maior redução de prurido ao fim de 6 semanas de tratamento. ${ }^{48}$

A terapêutica parece ser segura e efectiva também em crianças, com respostas completas a chegar aos $90 \%$ dos doentes tratados ao fim de 24 sessões. ${ }^{49}$ Ao longo de 2 anos de follow-up, constatou-se que a actividade da doença (SCORAD) e os níveis de prurido (VAS) se mantiveram significativamente inferiores aos determinados no início do estudo.

\subsection{UVA1}

Em ensaios duplamente cegos entre UVAl e nbUVB, a eficácia e a tolerância das duas modalidades foi comparável. ${ }^{50,51}$ Numa revisão sistemática de 19 ensaios randomizados demonstrou-se que UVA1 era tão eficaz como nbUVB na redução da actividade da doença. ${ }^{52}$ Contudo, alguns destes estudos não especificaram se os doentes tinham doença estável ou doença agudizada, pelo que parece não existir evidência robusta que suporte o uso de UVA 1 em detrimento de nbUVB nestes casos, como descrito anteriormente..$^{44}$

A principal limitação desta modalidade de fototerapia prende-se com a baixa disponibilidade nos diferentes centros especializados devido ao custo de aquisição do equipamento. Doses médias $\left(50 \mathrm{~J} / \mathrm{cm}^{2}\right)$ e altas $\left(130 \mathrm{~J} / \mathrm{cm}^{2}\right)$ de UVA1 
são igualmente eficazes, ${ }^{44}$ pese embora as energias mais elevadas impliquem uma maior exposição dos doentes a calor, que pode constituir factor de exacerbação da doença.

\subsection{PUVA}

A fotoquimioterapia com PUVA pode ser uma opção para doentes com doença grave e extensa, mas não existem muitos estudos que a comparem com outras modalidades de fototerapia.

Num ensaio aleatorizado com crossover em DA grave, foi demonstrado ter melhores respostas a curto e a longo prazo do que UVA1 em doses médias. ${ }^{53}$ Depois de 15 exposições, verificou-se que o PUVA reduziu o nível de SCORAD para valores significativamente inferiores aos alcançados com UVA1, sendo que a duração mediana de remissão foi de 4 semanas para os UVA1 e de 12 semanas para PUVA.

Um outro ensaio com apenas 12 doentes constatou que banho-PUVA é tão eficaz quando nbUVB em doentes com DA crónica grave. ${ }^{54}$ Não existem ensaios que comparem nbUVB à PUVA para a DA.

Apesar da eficácia desta opção terapêutica, existem algumas considerações de segurança relevantes que poderão relegá-la para segundo plano. $\bigcirc$ aumento da incidência de melanoma ${ }^{55}$ e de cancro cutâneo não melanoma ${ }^{56}$ verificados com PUVA parece ser inferior nas outras modalidades de fototerapia. ${ }^{57}$ Para além disso, o uso do agente fotossensibilizante pode desencadear cefaleias, náuseas e vómitos e, raramente, hepatotoxicidade, além de potenciar o risco de catarata inerente à exposição aos UVA. ${ }^{45}$

\subsection{UVAB}

A sustentação para a utilização deste regime de fototerapia é mais fraca do que para as modalidades mais recentes nbUVB e UVA 1. ${ }^{58}$ Poderá ser uma opção em locais onde as outras não estejam disponíveis.

\section{Compressas humedecidas (wet-wrap therapy)}

A terapêutica com compressas húmidas (wet-wrap therapy - WWT) é um método para controlar surtos de DA ou para DA refractárias às terapêuticas convencionais. ${ }^{59}$ Consiste na aplicação de um agente tópico (emoliente, dermocorticóide diluído ou não, ou inibidor da calcineurina) que é depois coberto por uma primeira camada de compressas ou roupa de algodão humedecidas, seguidas por uma segunda camada externa seca. A WWT parece funcionar através da oclusão do agente tópico com consequente aumento da sua penetração, reduzindo a perda de água transepidérmica e proporcionando uma barreira física contra o traumatismo de coceira. ${ }^{60}$ As compressas podem permanecer em contacto com a pele até 24 horas, de acordo com a tolerância e disponibilidade do doente. $O$ tratamento pode ser iniciado num breve internamento ou em ambulatório. ${ }^{61}$ O tratamento é considerado seguro mas os efeitos adversos possíveis incluem a absorção sistémica do corticosteróide, infecções bacterianas e o desconforto associado ao procedimento, ${ }^{60}$ efeitos que parecem estar relacionados com a duração do tratamento e com a potência do dermocorticóide utilizado. ${ }^{62-64}$

Numa meta-análise sobre a eficácia e segurança desta opção terapêutica na DA, verificou-se que a WWT era mais eficaz do que a corticoterapia tópica, mas a qualidade global dos estudos era baixa com amostras de apenas 19 a 51 doentes. ${ }^{65}$ A grande maioria dos trabalhos incluiu crianças, sendo escassos os de adultos.

Num estudo holandês, 12 adultos com DA refractária foram internados durante 7 dias para WWT com propionato de fluticasona 0,05\% diluída; depois da alta, mantiveram a WWT 4 dias por semana em ambulatório. As lesões melhoraram dramaticamente ao fim da primeira semana de tratamento, mas os níveis séricos matinais de cortisol reduziram de forma significativa. Ocorreram infecções num número não especificado de doentes adultos (foliculite, impetigo, infecção a Pseudomonas, celulite da face) e ainda supressão prolongada do eixo hipotálamo-hipofisário num doente que fazia paralelamente um inalador de fluticasona. ${ }^{62}$

Num outro estudo, 20 adultos foram submetidos a WWT com um dermocorticóide nos membros superior e inferior direitos, e os resultados foram comparados com os membros contralaterais onde apenas foi aplicado emoliente e corticoide tópico sem compressas húmidas oclusivas. Ao fim de 48-72 horas de tratamento, verificou-se redução de SCORAD em ambos os lados, mas os resultados do lado WWT foram significativamente melhores $(4,4$ vs 3,0, $p<0,011)$. Não foram observados efeitos adversos ou rebound no período de follow-up de 2 semanas. ${ }^{63}$

Num estudo mais recente, 12 adultos entre os 27 e os 85 anos foram submetidos a 2 sessões diárias de 2 horas de WWT com creme de halometasona e vaselina durante 7 dias. Todas as escalas de gravidade e qualidade de vida (SCORAD, VAS, IGA e DLQI) reduziram de forma significativa no final do tratamento. Para além da redução transitória de cortisol matinal no doente mais idoso que resolveu espontaneamente 2 semanas depois e de desconforto associado às compressas em 4 doentes, não ocorreram outros efeitos adversos. ${ }^{64}$

\section{Agentes sistémicos}

Os medicamentos imunomoduladores são dos principais fármacos do armamentário terapêutico para dermatoses inflamatórias graves e crónicas. O seu uso é muito comum em doenças bolhosas, granulomatosas ou na psoríase. Existem pouco estudos que os comparem de forma aleatorizada e controlada, pelo que é difícil determinar a eficácia relativa de cada um deles.

\subsection{Ciclosporina A}

A ciclosporina $A(C s A)$ é um potente imunossupressor que actua principalmente em células $\mathrm{T}$ por supressão da transcrição de mediadores inflamatórios. O fármaco liga-se a uma proteína intracelular, a ciclofilina, e este complexo inibe a calcineurina, uma molécula necessária para a transcrição de genes de citocinas. Pode ser usada como 


\section{Educação Médica Contínua}

terapêutica de curto-prazo, ou de longo prazo de forma intermitente, em doentes que não responderam a terapêuticas convencionais. ${ }^{66}$

Vários estudos controlados randomizados demonstraram que tanto crianças como adultos com DA grave refratária ao tratamento convencional podem beneficiar do tratamento a curto prazo com CsA oral. ${ }^{67}$ No entanto, os efeitos adversos (aumento do risco de infecções, náuseas, desconforto abdominal, hipertricose, parestesias, hipertensão, hiperbilirrubinémia, insuficiência renal e aumento do risco de neoplasias) motivam alguma preocupação no uso deste fármaco. Para além disso, a interrupção do tratamento pode resultar em recidiva da doença. ${ }^{68}$

Uma meta-análise de 15 estudos que incluiu 602 pacientes demonstrou que a CsA diminuiu consistentemente a gravidade da DA em todos os estudos analisados. ${ }^{67}$ Ao fim de 2 semanas de tratamento, os autores verificaram uma resposta dose-dependente com uma diminuição média combinada da gravidade da doença de 22\% (IC 95\%, 8\% a $36 \%$ ) com doses baixas de CsA ( $\leq 3 \mathrm{mg} / \mathrm{kg}$ ) e $40 \%$ (IC a $95 \%, 29 \%$ a $51 \%$ ) em dosagens $\geq 4 \mathrm{mg} / \mathrm{kg}$. Após 6 a 8 semanas, a eficácia combinada de ambas as doses foi de $55 \%$ (IC 95\%, 48\% a 62\%).

A CsA é geralmente iniciada a $5 \mathrm{mg} / \mathrm{kg} / \mathrm{dia}$, dividida em 2 tomas. As funções renal e hepática devem ser monitorizadas. $\bigcirc$ fármaco pode ser reduzido $1 \mathrm{mg} / \mathrm{kg} /$ dia cada um a três meses. ${ }^{69} \mathrm{Em}$ alternativa, uma dose inicial de $3 \mathrm{mg} /$ $\mathrm{kg}$, seguida do aumento da dose de acordo com a resposta do doente, mostrou ser tão segura e eficaz como uma dose inicial de $5 \mathrm{mg} / \mathrm{kg}$ seguida de redução. ${ }^{70}$

A eficácia da CsA a longo prazo foi avaliada em estudos com seguimento de aproximadamente 1 ano. ${ }^{70-72} \mathrm{~A}$ melhoria média relativa foi de cerca de 50\%. No entanto, verificaram-se taxas de abandono de $35 \%,{ }^{70} 62 \%{ }^{71}$ e $28 \%{ }^{72}$ A taxa de recidiva após a descontinuação do tratamento (aumento da gravidade da doença em mais de 75\% do índice de gravidade basal individual) observou-se em $86 \%$ ao longo de 9 meses. $^{72}$

O uso de CsA foi também avaliado em vários ensaios comparativos aleatorizados. Um deles comparou a CsA (3 $\mathrm{mg} / \mathrm{kg} / \mathrm{dia}$ ) e o micofenolato de sódio ( $1440 \mathrm{mg} / \mathrm{dia}$ ) em 55 adultos com DA grave após indução de remissão com CsA ( $5 \mathrm{mg} / \mathrm{kg} / \mathrm{dia}$ ). ${ }^{7}$ Após um aumento dos sintomas durante as primeiras 6 semanas de terapêutica, a CsA e o micofenolato de sódio foram igualmente eficazes na manutenção da melhoria. Os efeitos adversos foram ligeiros e transitórios em ambos os grupos. Durante a fase de manutenção, $62 \%$ dos doentes no grupo da CsA desenvolveram hipertricose e $15 \%$ hipertensão que necessitou de tratamento. $O$ principal efeito adverso do micofenolato foi a fadiga, reportada em $46 \%$ dos doentes.

Num ensaio aleatorizado e controlado que avaliou 72 doentes em terapêutica intermitente, a CsA foi superior a UVAB na indução de um maior número de dias de remissão ao longo de 1 ano, não havendo contudo diferenças em termos de qualidade de vida. ${ }^{74}$ Foi detectado um aumento significativo dos níveis de creatinina sérica e hipertensão ligeira a moderada em 2 e 7 doentes no grupo CsA, respectivamente.

O achado de que a glucosamina mostra efeitos imunomoduladores em modelos inflamatórios animais, ${ }^{75}$ motivou a pesquisa do seu efeito sinérgico com a CsA. ${ }^{76,77} \mathrm{Um}$ ensaio aleatorizado, duplamente cego, controlado por placebo, comparou 2 grupos de doentes com DA grave, um tratado com CsA em baixa dose $(2 \mathrm{mg} / \mathrm{kg} / \mathrm{dia})+$ glucosamina $(25 \mathrm{mg} / \mathrm{kg})$, com outro tratado com a mesma dose de CsA + placebo. ${ }^{77}$ Ao fim de 8 semanas, mostraram meIhorias 15 (93,8\%) dos 16 doentes no primeiro grupo, em 4 com redução superior a 50\% do SCORAD; no segundo grupo, 10 (58,8\%) de 17 doentes melhoraram, apenas um com melhoria superior a 50\% do SCORAD. No cômputo geral, houve uma redução de $34 \%$ do SCORAD no primeiro grupo e de $15 \%$ no segundo. A glucosamina combinada com a CsA não aumentou os eventos adversos nem os níveis séricos de ciclosporina em comparação com a CsA isolada. Os autores concluíram que a associação de glucosamina pode ser útil para permitir o uso prolongado da CsA em pacientes com $A D$ moderada a grave.

A CsA foi comparada com o metotrexato (MTX) em adultos com DA grave. ${ }^{78}$ Noventa e sete doentes foram aleatorizados para receber MTX (15 mg/semana) ou CsA (2,5 mg/ $\mathrm{kg} /$ dia) durante 8 semanas: a resposta SCORAD 50 (uma melhoria de $50 \%$ neste índice de gravidade) foi significativamente superior no grupo CsA ( $8 \%$ MTX vs $42 \%$ CsA). Na semana 8 , os doentes que não tinham atingido SCORAD 50 viram as doses dos fármacos aumentar para os $25 \mathrm{mg} /$ semana no grupo MTX e $5 \mathrm{mg} / \mathrm{kg} /$ dia no CsA durante mais 16 semanas. No fim desse período, os doentes sob a nova dose de MTX atingiram uma taxa de EASI 50 sobreponível aos de CsA (92 vs 87\%). Contudo, a taxa de eventos adversos foi significativamente inferior no grupo MTX (30 vs 55\%, $p<0,0001)$.

Também neste ano, num estudo retrospectivo, foram avaliados os perfis de tratamento dos 2 medicamentos. ${ }^{79} \mathrm{Os}$ doentes sob MTX permaneciam mais tempo controlados sob terapêutica quando comparados com os que faziam CsA (23 vs 8 meses, $p<0,0001$ ) e o intervalo de tempo entre a interrupção do fármaco e a necessidade de reintroduzir novo fármaco foi superior no grupo MTX (12 vs 2 meses).

\subsection{Azatioprina}

A azatioprina (AZA) é um antagonista do metabolismo das purinas que causa imunossupressão por inibição da proliferação de células T. É metabolizado pela enzima tiopurina-S-metiltransferase (TMPT). Os efeitos adversos incluem alterações gastrintestinais, mielossupressão, hepatotoxicidade, e o aumento da susceptibilidade a infecções e neoplasias. A determinação pré-tratamento da atividade da TPMT pode ser útil para ajustar a dose e reduzir o risco de mielotoxicidade. ${ }^{80}$ Os níveis séricos de atividade de TPMT variam de acordo com polimorfismos de DNA, com níveis normais em $80 \%$, baixos em $10 \%$, altos em $9 \%$ e indetectáveis em $0,5 \%$ 


\section{Educação Médica Contínua}

da população. ${ }^{81}$ Os doentes com níveis mais baixos de TPMT iniciam habitualmente uma dose menor de AZA para reduzir o risco de efeitos adversos. Hemograma e enzimologia hepática deverão ser monitorizados regularmente. ${ }^{82}$

Num ensaio controlado duplamente cego de 37 adultos com DA grave, observou-se uma redução média da actividade da doença em $27 \%$ após 12 semanas de tratamento com 2,5 mg/kg de AZA.83 Contudo, registou-se uma taxa de abandono de $43 \%$, tendo 4 doentes sido retirados prematuramente devido a eventos adversos. Num outro ensaio com as mesmas características mas com uma amostra maior de doentes e com adaptação da dose de AZA à actividade da TPMT, ${ }^{84}$ a taxa de abandono foi menor (14\%); a redução da actividade da doença foi de $37 \%$ mas houve uma grande variabilidade de respostas entre doentes.

A AZA e MTX foram igualmente eficazes aos 3 meses em 42 doentes não respondedores ou intolerantes à CsA, com melhoria média de SCORAD de $39 \%$ e $42 \%$ respectivamente, ${ }^{71}$ sem diferença nas taxas de eventos adversos. Na fase subsequente de seguimento ao longo de 5 anos, já em open-label, ${ }^{86}$ verificou-se a interrupção do tratamento com MTX ( $n=12)$ por ineficácia $(n=5)$ ou eventos adversos ( $=4)$ e, em menor medida, por controlo da DA ( $n=2)$; a interrupção da AZA $(n=17)$ ocorreu por ineficácia $(n=7)$, DA controlada $(n=6)$ e, em menor medida, por eventos adversos ( $\mathrm{n}=1)$. O MTX revelou uma sobrevida superior a AZA (28,8 vs 11,5 meses) com eficácia semelhante (redução absoluta média de SCORAD de 32,1 nos 2 grupos).

Numa revisão sobre o uso da AZA na DA, ${ }^{87}$ foram encontradas alterações das transaminases entre 10\% a $36 \%$ dos doentes, alterações no hemograma em até $77 \%$ e náuseas em até $57 \%$, sendo sugeridas uma revisão analítica e a determinação dos níveis de TPMT antes de iniciar tratamento. A dose inicial de AZA deverá ser de 2 a 2,5 mg/ $\mathrm{kg}$ em doentes com níveis normais de TPMT e de 1 a $1,5 \mathrm{mg} / \mathrm{kg}$ se for detectado um polimorfismo; se não forem detectados níveis de TPMT, o fármaco não deverá ser iniciado. Hemograma e transaminases deverão ser determinados às semanas 1, 3 e 7 e depois a cada 3 meses; alterações nas análises (aumento das transaminases para o dobro dos valores de referência, linfopenia ou neutropenia), deverão motivar a suspensão do fármaco por 1 semana. Se as alterações tiverem revertido no fim desse período, o medicamento poderá ser retomado com redução da dose em 0,25 a 0,5 mg/kg. Alterações mantidas ou reiteradas dos valores analíticos poderão levar à suspensão definitiva de AZA.

\subsection{Micofenolato de mofetil}

micofenolato de mofetil (MMF) inibe a síntese de purinas em linfócitos $\mathrm{B}$ e T através do seu metabolito activo, o ácido micofenólico. O seu mecanismo de acção é comparável ao da AZT mas é mais selectivo, o que explica o melhor perfil de segurança e a ausência de toxicidade em indivíduos com deficiência de TPMT. ${ }^{88}$ Os efeitos adversos mais significativos são mielossupressão, desconforto gastrintestinal e infecções. O MMF é teratogénico, pelo que mulheres em idade fértil devem seguir uma contracepção segura. As doses padrão variam entre 0,5 e 1,5 g duas vezes ao dia. Está disponível uma formulação do metabolito activo do MMF em comprimidos revestidos (micofenolato de sódio enteric-coated (EC-MPS) $1440 \mathrm{mg} / \mathrm{dia}$ ) com vista a diminuir a gravidade dos sintomas gastrintestinais e aumentar a tolerabilidade. Ainda que a farmacocinética divirja ligeiramente da fórmula tradicional, poderá ser uma escolha mais popular no futuro. ${ }^{89}$

Estudos retrospectivos não controlados de pequena dimensão demonstram a eficácia do fármaco na DA grave. Num estudo com 20 doentes consecutivos sob MMF $1 \mathrm{~g}$ bidiário, 17 responderam nas primeiras 4 semanas de tratamento; destes, 10 tiveram remissão completa da doença, que permitiu a interrupção do fármaco, enquanto 7 doentes mantiveram controlo da DA usando MMF como terapêutica de manutenção. ${ }^{90}$ Num outro estudo retrospectivo de 104 doentes tratados com MMF ou micofenolato de sódio enteric-coated (EC-MPS), 82 descontinuaram a terapêutica, 36 (44\%) por ineficácia, 18 (22\%) por efeitos adversos e 11 doentes (13\%) por remissão completa da doença..$^{91}$

Num estudo comparativo, o EC-MPS $1440 \mathrm{mg} / \mathrm{dia}$ foi tão eficaz como a CsA $3 \mathrm{mg} / \mathrm{kg} /$ dia na terapêutica de manutenção a longo prazo em 55 adultos com DA grave. ${ }^{73}$

\subsection{Metotrexato}

O MTX é um análogo do ácido fólico que bloqueia enzimas dependentes do folato para a síntese de DNA. É um inibidor potente e irreversível da dihidrofolato-reductase, a enzima responsável pela síntese de tetrahidrofolato, um cofactor necessário para a síntese de purinas e pirimidinas. Este efeito inibe sobretudo células com elevado índice proliferativo, exercendo efeitos anti-neoplásicos. Nos linfócitos, ainda que o efeito anti-proliferativo possa explicar a acção anti-inflamatória, esta propriedade estará mais dependente do aumento da adenosina. ${ }^{92} \mathrm{O}$ perfil de segurança está bem estabelecido na Dermatologia dada a extensa utilização na psoríase: citopénia, alterações gastrintestinais, hepatotoxicidade, teratogenecidade e fibrose pulmonar. ${ }^{93}$

A eficácia do MTX na DA grave está documentada em ensaios comparativos com $\mathrm{AZA}^{71}$ e $\mathrm{Cs}^{94,78}$ e nalgumas séries curtas de casos. ${ }^{95-97}$ Num estudo aberto prospectivo envolvendo 12 doentes, observou-se uma diminuição da actividade da doença em $52 \%$ às 24 semanas, com doses medianas de $15 \mathrm{mg} / \mathrm{semana} ; 8$ doentes mantiveram essa melhoria 12 semanas após a interrupção da terapêutica. ${ }^{95}$ Num estudo retrospectivo 15 de 20 doentes tratados por via intramuscular com doses semanais de 7,5 a $25 \mathrm{mg}$ de MTX, demonstraram melhoria clínica superior a $70 \%$ aos 3 meses de terapêutica. ${ }^{97}$ Noutro estudo retrospectivo com 10 a $25 \mathrm{mg} / \mathrm{semana}$ de MTX durante 8 a 12 semanas em 20 doentes com DA moderada a grave, $80 \%$ tiveram reduções médias de SCORAD e DLQI em 44\%. ${ }^{96}$

O MTX (7,5 a 25 mg/semana) é uma opção de segunda linha eficaz e bem tolerada mas com um início lento de acção. A melhoria dos sintomas nos respondedores pode 


\section{Educação Médica Contínua}

ser observada entre as 2 semanas e os 3 meses. Os estudos sugerem que os doentes que não respondam a $15 \mathrm{mg}$ de MTX por semana aos 3 meses, provavelmente não melhorarão com o aumento da dose. ${ }^{95}$

\subsection{Corticosteróides}

Há dados limitados sobre a eficácia dos corticosteróides sistémicos no tratamento da DA, ${ }^{98-100}$ apesar do seu uso disseminado. A experiência clínica mostra que podem controlar de forma rápida e eficaz os sintomas da doença. Infelizmente, o carácter crónico e recidivante da doença leva a que tratamentos a médio ou a longo prazo resultem frequentemente nos conhecidos efeitos adversos (ex. osteoporose, cataratas, hiperglicémia, alterações neuro-psiquiátricas, linfopenia). ${ }^{101} \mathrm{Um}$ ciclo curto é por vezes utilizado para controlar uma exacerbação aguda e grave da doença, ainda que um rebound possa acontecer com a sua suspensão. No longo prazo, o uso de outros imunossupressores deve ser considerado com a eliminação dos corticosteróides sistémicos. ${ }^{102}$

Em 2010, um estudo comparou prednisolona oral $(0,5$ a $0,8 \mathrm{mg} / \mathrm{kg}$ em redução progressiva ao longo de 2 semanas) e CsA (4 mg/kg durante 6 semanas) em 66 adultos com DA grave. $O$ estudo foi prematuramente interrompido uma vez que quase todos os doentes tratados com prednisolona tiveram um rebound significativo após suspensão do tratamento, apesar da manutenção de dermocorticóides, emolientes e anti-histamínicos. Dos 38 doentes que concluíram o ensaio, apenas 1 do grupo prednisolona (5\% de 21) e 6 do grupo CsA (35\% de 17) atingiram remissão estável da doença. $O$ estudo sugere superioridade da $\operatorname{CsA}(p=0,03)$ e os autores recomendam a não utilização de prednisolona nestes doentes. ${ }^{100}$

Muito recentemente, o Conselho Internacional de Eczema publicou um consenso sobre a utilização dos corticosteróides sistémicos na DA grave ${ }^{103}$ e concluíram que devem ser globalmente evitados, mas que podem ser pontualmente utilizados em determinadas circunstâncias: a falta de outras opções de tratamento, a transição para outras terapêuticas sistémicas ou fototerapia, durante crises agudas que necessitem de alívio imediato, em antecipação a um evento de vida major ou em casos muito graves. $O$ tratamento deve ser limitado a ciclos curtos. A recomendação de não utilização em crianças não foi consensual e foi baseada sobretudo na opinião de peritos.

\subsection{Apremilast}

O apremilast é um inibidor da fosfodiesterase tipo 4 (PDE4) indicado para o tratamento da psoríase moderada a grave e artrite psoriática. O racional subjacente à sua utilização na DA baseia-se na observação que doentes com patologias inflamatórias, como asma e DA, apresentam níveis elevados de PDE4 quando comparadas com controlos. Os efeitos dessa enzima incluem a redução AMP cíclico, supressão da proteína cinase $A$ e no consequente aumento dos níveis de citocinas pró-inflamatórias. ${ }^{104}$
Em 2012 foram publicados 2 ensaios que investigaram a sua segurança e eficácia na DA. No primeiro, 16 doentes receberam doses de 20 ou $30 \mathrm{mg}$ bidiárias ao longo de 3 e 6 meses, com reduções significativas nos índices de gravidade da doença e na melhoria de qualidade de vida em ambos os grupos (EASI de 25 para 16, $p=0,002$; VAS de 52 para $32 \mathrm{~mm}, p=0,003$; DLQI de 12 para $5, p=$ $0,001)$. As náuseas foram o efeito adverso mais reportado, mais frequente na dose superior (10\% vs 90\%). ${ }^{105}$ Num ensaio de fase 2 com 10 doentes com a dose de 20 mg bidiária durante 12 semanas, os resultados revelaram-se apenas minimamente eficazes com apenas $20 \%$ dos doentes a atingir os endpoints primário e secundário (redução de 2 pontos do IGA, redução do EASI em $75 \%$ ou $50 \%$ ), sendo os efeitos adversos mais comuns as cefaleias e as náuseas. ${ }^{106}$

Todavia, nenhum destes ensaios foi controlado com placebo, as amostras foram muito pequenas e o período de seguimento não ultrapassou os 6 meses, pelo que pouco se pode inferir sobre a segurança e eficácia do apremilast na DA moderada a grave. Desde estão, foram reportados raros casos clínicos com resultados favoráveis, ${ }^{107-109}$ o que pode corresponder a um viés de publicação neste contexto.

\subsection{Agentes biotecnológicos}

Os agentes biotecnológicos (biológicos) incluem proteínas recombinantes, anticorpos monoclonais ou proteínas de fusão que se ligam a proteínas específicas, receptores celulares, citocinas ou outros mediadores. Têm sido utilizados com sucesso para tratar múltiplas patologias imuno-mediadas, nomeadamente a psoríase. Nos últimos anos, vários pequenos estudos não controlados foram publicados, sugerindo o efeito de alguns agentes biológicos na DA. Infelizmente, até há muito pouco tempo, não havia estudos controlados com estes fármacos, nem tão pouco moléculas desenvolvidas especificamente para a DA.

\subsubsection{Rituximab}

O rituximab é um anticorpo monoclonal quimérico anti-CD20 que elimina linfócitos B originalmente desenvolvido para tratamento de linfomas. Foi identificado como uma opção em doentes com DA grave, particularmente naqueles com níveis de lgE elevados. Num trabalho de 2008, 6 doentes com DA grave tratados com 2 doses de $1000 \mathrm{mg}$ de rituximab com 2 semanas de intervalo tiveram uma meIhoria marcada entre as 4 e as 8 semanas, com redução de todos os parâmetros de gravidade avaliados - EASI, alterações histopatológicas, expressão de IL-5 e IL-13, e níveis de IgE totais. Ocorreram infecções em 2 doentes controladas com antibiótico e náuseas e vómitos num terceiro doente. ${ }^{110}$ fármaco foi inclusivamente eficaz e seguro numa grávida com DA grave. ${ }^{111}$

Esta eficácia não foi contudo documentada num relato de 2 doentes que receberam uma dose inferior de rituximab (500 mg por dose com 2 semanas de intervalo): um doente melhorou o SCORAD de 99 para 58 à semana 10, mas o outro agravou de 63 para $74 .{ }^{112}$ Mais recentemente, numa 
série de 3 casos nenhum dos doentes melhorou, ${ }^{113}$ pelo que o benefício terapêutico do rituximab na DA grave carece de evidência científica.

\subsubsection{Alefacept}

O alfacept é uma proteína de fusão LFA-3/lgG1 totalmente humana que inibe a ativação das células $T$ e leva à apoptose de células $T$ de memória. $O$ tratamento de 10 doentes com DA moderada a grave com alefacept $15 \mathrm{mg}$ intramuscular semanalmente durante 12 semanas resultou na redução significativa dos sintomas em todos eles: a melhoria média de EASI foi de $78 \%$ na semana $12 .{ }^{114}$ Outro grupo, que utilizou uma dose superior e mais prolongada de alefacept (30 mg semanais durante 8 semanas, seguido de 15 ou $30 \mathrm{mg}$ durante mais 8 semanas de acordo com a resposta), reportou melhoria clínica em apenas 2 dos 9 doentes tratados. ${ }^{115} \bigcirc$ fármaco foi bem tolerado em ambos os estudos.

\subsubsection{Infliximab}

infliximab, um anticorpo monoclonal anti-TNFalfa, foi estudado em 9 doentes adultos com DA moderada a grave refratária às terapêuticas convencionais. ${ }^{116} \bigcirc$ fármaco foi administrado durante 38 semanas com as doses preconizadas para a psoríase vulgar e os doentes foram reavaliados 8 semanas depois da interrupção. Todos os parâmetros clínicos melhoraram durante a fase de indução, mas essa melhoria não foi sustentada durante a fase de manutenção: apenas 2 doentes mantiveram respostas no fim do seguimento. Estão descritos vários casos de erupções semelhantes à DA em doentes com psoríase sob terapêutica com infliximab. ${ }^{117-119} \mathrm{O}$ benefício terapêutico do infliximab no tratamento da DA parece portanto improvável.

\subsubsection{Omalizumab}

Omalizumab é um anticorpo monoclonal humanizado anti-lgE, indicado na terapêutica da asma alérgica e da urticária crónica espontânea. Os resultados em pacientes com DA moderada a grave são variáveis. ${ }^{120-122}$ O racional da sua utilização prende-se com a eficácia do omalizumab no tratamento da asma e da rinite alérgica que são componentes da tríade alérgica clássica que partilham alguns dos mecanismos inflamatórios com a DA. ${ }^{122}$ De facto, alguns doentes com DA têm níveis séricos de lgE muito elevados e sensibilizações a alergénios alimentares e ambientais. Todavia, o papel e significado temporal das IgE na DA está ainda por esclarecer. ${ }^{123}$

As pequenas séries disponíveis, com amostras entre 7 a 21 doentes, mostram um benefício na terapêutica continuada a médio / longo-prazo, com doses entre os 150 e os 450 mg de 2 em 2 semanas, ${ }^{122,124-128}$ sem efeitos adversos significativos associados. Contudo, estes resultados foram contrariados pelo único estudo aleatorizado, duplamente-cego, controlado por placebo em 20 adultos com DA crónica, que não demonstrou um efeito superior do omalizumab ao longo de 16 semanas. ${ }^{129}$

Estes achados conflituosos levaram alguns investigadores a procurar identificar potenciais marcadores bioquímicos que pudessem ajudar na identificação de subgrupos de doentes que beneficiem deste anticorpo para o controlo da doença. Os resultados não parecem ter relação com o nível sérico basal de lgE, nem a resposta com a redução do mesmo; o rácio de mRNA lgE/lgG mostrou associação com uma resposta clínica positiva mas falhou na identificação dos doentes não respondedores. ${ }^{125} \mathrm{Um}$ outro grupo sugere que os respondedores são caracterizados pela ausência de mutações de filagrina e alterações dos perfis de metabolitos dos lípidos com níveis elevados de glicerofosfolípidos. ${ }^{126} \mathrm{~A}$ utilização de omalizumab nesta patologia carece ainda de ensaios mais robustos e da caracterização adequada da subpopulação que pode dele beneficiar.

\subsubsection{Mepolizumab}

A IL-5 é uma citocina fundamental para o crescimento, diferenciação e migração de granulócitos eosinofílicos, que desempenham um papel relevante na patogénese da DA. Duas doses únicas de $750 \mathrm{mg}$ de mepolizumab (anticorpo monoclonal humanizado recombinante anti-(L-5), administradas com intervalos de uma semana, foram testadas num estudo aleatorizado controlado com placebo em 40 doentes com DA moderada a grave. Às 2 semanas verificou-se uma diminuição significativa dos eosinófilos no sangue periférico mas a melhoria clínica foi modesta $(<50 \%$ melhoria do PGA) em comparação com o grupo placebo. ${ }^{130}$ Depois destes resultados iniciais, não se encontra na literatura nenhum outro trabalho com o uso do mepolizumab na DA.

\subsubsection{Dupilumab}

A DA é caracterizada imunologicamente por uma activação excessiva de células $T$, com infiltração cutânea significativa de células $T$ e células dendríticas. Ocorre um aumento de expressão de citocinas Th2 nas lesões agudas (IL-4, IL-5 e IL-13) e uma correspondente diminuição de citocinas Th1. ${ }^{131}$ Este perfil de citocinas, além de activar células inflamatórias envolvidas em reacções alérgicas (eosinófilos, basófilos, mastócitos e células $B$ produtoras de $\lg \mathrm{E}$ ), tem efeitos específicos na epiderme, como a supressão de diferenciação de queratinócitos e a interrupção da produção do péptido antimicrobiano, fenómenos preponderantes no fenótipo cutâneo da DA. ${ }^{132,133}$

O dupilumab é um anticorpo monoclonal totalmente humanizado que se liga à subunidade alfa do receptor da IL-4 e bloqueia a sinalização de IL-4 e IL-13. Estudos iniciais demonstraram eficácia em doentes com asma e sinusite crónica com polipose nasal, patologias mediadas por citocinas Th2. ${ }^{134}$ Os estudos de fase 1 e 2 na utilização na DA moderada a grave começaram em 2014 e demonstraram uma eficácia dose-dependente na melhoria dos sintomas em adultos. ${ }^{135,136}$

Um estudo em 18 doentes com DA moderada a grave mostrou uma melhoria estatisticamente significativa e dependente da dose no transcriptoma da DA antes e depois do tratamento com dupilumab, alterações moleculares que 


\section{Educação Médica Contínua}

espelharam a melhoria clínica observada. ${ }^{137} \mathrm{O}$ dupilumab suprimiu também a expressão de mRNA de genes relacionados com a ativação de células $T$, células dendríticas, eosinófilos, vias inflamatórias e citocinas Th2. Foi igualmente demonstrado que o dupilumab reverteu o fenótipo epidérmico das lesões de DA com possível restabelecimento da barreira cutânea: regulação negativa dos genes responsáveis pela hiperplasia epidérmica (genes S100A e K16) e aumento nos níveis de claudina, loricrina, filagrina e produtos lipídicos.

Nos dois estudos de fase 3 aleatorizados e controlados por placebo (SOLO1 E SOLO2) foram avaliados 1379 doentes com DA moderada a grave inadequadamente controlados com medicamentos tópicos. Dupilumab $300 \mathrm{mg}$ foi administrado por via subcutânea semanal ou quinzenalmente. No SOLO1, 37\% dos doentes que receberam dupilumab semanalmente e $38 \%$ dos que receberam dupilumab a cada duas semanas obtiveram IGA de 0 ou 1 (resolução completa ou quase completa dos sintomas), em comparação com $10 \%$ dos que receberam placebo $(p<0,001$ para ambas as comparações com placebo). ${ }^{138}$ Resultados semeIhantes foram relatados no SOLO2, com 36\% dos doentes que receberam dupilumab semanalmente ou a cada duas semanas a alcançar uma IGA de 0 ou 1 , em comparação com $8 \%$ dos que receberam placebo $(p<0,001) .{ }^{138}$ Para além disso, verificou-se uma melhoria de pelo menos $75 \%$ no EASI às 16 semanas em significativamente mais doentes dos grupos dupilumab do que nos do grupo placebo ( $p$ $<0,001$ para todas as comparações). Os doentes reportaram uma redução substancial do prurido, uma melhoria de sintomas de ansiedade e depressão, da qualidade do sono e da qualidade de vida global. ${ }^{138}$ Estes resultados foram significativos apenas nos regimes de $300 \mathrm{mg}$ e não no de 100 $\mathrm{mg}$ estudado num ensaio de fase 2. ${ }^{136}$

Do ponto de vista de segurança, muito embora a taxa de efeitos adversos tenha sido baixa e sobreponível à do placebo, ocorreu mais frequentemente nasofaringite, cefaleias e reacções no local da injecção nos doentes tratados com dupilumab. ${ }^{135}$ Estes efeitos foram globalmente classificados como ligeiros ou moderados e autolimitados. Os efeitos adversos graves foram superiores no grupo placebo $(11,2 \%$ vs 1,5\%): a generalidade estava relacionada com um aumento do número de infecções e exacerbações da DA, em linha com a melhoria da barreira cutânea conseguida pelo fármaco. ${ }^{135} \mathrm{Um}$ dos ensaios já aludidos e os de fase 3 revelaram as mesmas taxas de efeitos adversos mas identificaram a conjuntivite e as infecções do tracto respiratório superior como eventos mais frequentes do que no grupo placebo. ${ }^{137,138}$

Num estudo fase 3 de longo prazo, o dupilumab 300 $\mathrm{mg}$ semanal ou quinzenal, associado a corticosteróides ou imunomoduladores tópicos, demonstrou eficácia e segurança sustentadas durante um período de 52 semanas de tratamento. ${ }^{139}$ À semana 16, a taxa de doentes que atingiram IGA 0/1 do grupo dupilumab $300 \mathrm{mg}$ semanal (39\%) e quinzenal $(39 \%)$ foi superior ao grupo placebo (12\%; $p$ $<0,0001)$; verificou-se uma redução em $75 \%$ do EASI em
$64 \%, 69 \%$ e $23 \%$ dos doentes, respectivamente $(p<0,0001)$. A taxa de eventos adversos ligeiros/moderados e graves foi sobreponível nos 3 grupos.

Em Março de 2017, a FDA aprovou o dupilumab para o tratamento de adultos com DA moderada a grave não adequadamente controlados com terapias tópicas prescritas ou para os quais esses tratamentos não são apropriados e, em Setembro de 2017, seguiu-se a aprovação da EMA. A dose inicial recomendada é de $600 \mathrm{mg}$ (duas injeções subcutâneas de $300 \mathrm{mg}$ ), seguida de dupilumab $300 \mathrm{mg}$ administrado a cada duas semanas.

Estão a decorrer vários ensaios de fase 3 sobre a eficácia e segurança do dupilumab em idade pediátrica. ${ }^{140-143}$ No único concluído, o fármaco foi usado em adolescentes dos 12 aos 18 anos 141 e os resultados, apresentados no $27^{\circ}$ Congresso Europeu de Dermatologia e Venereologia de 2018 em Paris, mostram-se sobreponíveis aos encontrados em adultos. ${ }^{144}$ Há ensaios a recrutar crianças dos 6 aos 12 anos 142 e outro dos 6 meses aos 6 anos de idade. ${ }^{143}$

\section{Outras terapêuticas \\ 11.1 Imunoglobulina intravenosa}

A imunoglobulina intravenosa (IGIV), que tem efeitos imunomoduladores em altas doses $(2 \mathrm{~g} / \mathrm{kg}$ ) e é usada em variadas patologias inflamatórias dermatológicas, foi referenciada como uma possibilidade de sucesso nalguns relatos de casos e em pequenos estudos não controlados, com respostas superiores em crianças do que em adultos. ${ }^{145}$ Contudo, não se verificou a melhoria esperada num pequeno ensaio aleatorizado, cego para os avaliadores, comparativo com a ciclosporina. ${ }^{146}$

\subsection{Fotoferese extracorporal}

O tratamento com fotoferese extracorporal (ECP) implica a irradiação de células mononucleares do sangue periférico previamente expostas ao 8-metoxipsoraleno e posteriormente devolvidas ao doente por infusão. $O$ efeito terapêutico da ECP na DA parece estar relacionado com a promoção de produção de células $T$ reguladoras (T-reg) e citocinas imunossupressoras ou imunomoduladoras, com uma normalização do equilíbrio imunológico Th 1 / Th2.147 A ECP melhorou a DA grave refratária em poucos estudos pequenos e não controlados com amostras até 14 doentes. ${ }^{148}$

No maior ensaio prospectivo aberto com 35 doentes, a ECP levou a uma redução significativa do SCORAD com 6 a 10 ciclos de tratamento $(74,4$ vs $36,8, p<0,05) .{ }^{149}$ Num outro ensaio de menor dimensão em que se comparava CsA e ECP, os investigadores verificaram uma redução marcada do SCORAD e do prurido sem diferença estatística entre os grupos; a redução do IGA foi significativamente maior no grupo ECP. ${ }^{150}$

\subsection{Imunoterapia específica}

A sensibilização a alergénios inalados, como ácaros do pó da casa ou pólens, é comum em doentes com DA e a 


\section{Educação Médica Contínua}

exposição pode causar surtos de DA nalguns doentes. ${ }^{30,31} \mathrm{~A}$ imunoterapia específica (SIT) baseia-se no princípio básico da indução de tolerância a alergénios através da sua administração subcutânea ou sublingual em doses repetidas e crescentes. Tem eficácia demonstrada na rinite alérgica, na asma e na anafilaxia causada por venenos. ${ }^{151}$

É controversa a sua eficácia na DA. Embora várias revisões sistemáticas tenham mostrado que a SIT poderá melhorar o curso da doença, muitos estudos são não controlados, não aleatorizados, ou observacionais e, portanto, com potencial de viés. ${ }^{152,153}$ Além disso, os efeitos desta modalidade terapêutica nunca foram quantitativamente determinados, devido ao pequeno número de ensaios clínicos randomizados (RCT), com desenhos demasiado heterogéneos. Numa meta-análise recentemente publicada sobre o efeito da SIT na DA, os autores identificaram 12 RCT mas concluíram que os resultados são muito heterogéneos e que a evidência da eficácia da SIT na DA é baixa, pelo que não deve ser recomendada para a generalidade dos doentes. ${ }^{154}$

\subsection{Imunoadsorção}

Ainda que o papel e significado temporal das IgE na DA esteja ainda por esclarecer, ${ }^{123}$ muitos autores continuam a explorar a depleção desta imunoglobulina como opção terapêutica, obtendo resultados muito pouco consistentes. A imunoadsorção, que permite a redução de imunoglobulina global ou selectiva de $\lg$, foi outra das opções exploradas neste contexto.

Numa revisão sobre os 6 estudos publicados com 71 doentes tratados, é descrita uma deplecção de lgE a variar entre $64 \%$ a mais de $90 \%$. Em termos de eficácia clínica, quase todos os doentes tiveram uma redução da actividade da doença (reduções de SCORAD entre $27 \%$ e $88 \%$ ). Contudo, isto traduziu-se numa redução de SCORAD superior a $50 \%$ em 7 dos 43 doentes tratados com imunoadsorção não selectiva, e em apenas 2 dos 28 tratados com imunoadsorção selectiva de $\lg$. $^{155}$

\section{Fármacos emergentes \\ 12.1. Inibidores da Janus cinase (baricitinib / upadacitinib / tofacitinib)}

A pele lesada com DA contém elevados níveis de citocinas inflamatórias, incluindo Th2 (IL-4, IL-13, IL-31), Th22 (IL-22), e Th1 (IFN $\gamma$ ), muitas delas libertadas por meio da sinalização intracelular mediada pela Janus kinase (JAK) / signal transducer and activator of transcription (STAT). ${ }^{156}$ Qualquer fármaco desta classe funciona por inibição das JAK e nenhum é considerado biotecnológico: a síntese é química convencional, não sendo criados em células como os agentes biológicos.

O baricitinib é um inibidor selectivo das JAK1 e JAK2, presentemente aprovado no tratamento da artrite reumatóide moderada a grave. Num ensaio de fase 2 com 124 doentes com DA moderada a grave, o baricitinib oral foi superior ao placebo na melhoria dos sintomas.157 Estes resultados foram significativos para EASI-50 (61\% vs 37\%, $p=, 027)$ e na melhoria do prurido e do sono, efeitos que foram dose-dependentes (2 vs $4 \mathrm{mg}$ ).

O upadacitinib é um inibidor da JAK 1 oral que estás presentemente em investigação para a artrite reumatoide e doença inflamatória intestinal. Num poster apresentado no Congresso da Academia Americana de Dermatologia (AAD) de 2018, foram revelados os resultados de um estudo de fase 2 com 166 doentes com DA. ${ }^{158}$ Às 16 semanas, um número significativamente maior de doentes sob upadacitinib atingiram EASI-90 e IGA 0 ou 1 do que aqueles sob placebo $(50 \%$ vs $2 \%, p<0,001$, para ambos os índices na dose de $30 \mathrm{mg}$ ).

O tofacitinib foi o primeiro fármaco desta classe e está aprovado no tratamento de artrite reumatóide, colite ulcerosa e artrite psoriática. Tem sido experimentado com algum sucesso em patologia cutânea imuno-mediada, nomeadamente na psoríase (iá em ensaios de fase 3), alopécia areata e vitiligo. ${ }^{159}$ Num estudo observacional de 6 doentes consecutivos com DA moderada a grave que não tinham respondido às terapêuticas convencionais, verificou-se uma redução de SCORAD de 36,5 para 12,2 ( $p<0,05$ ), sem efeitos adversos associados. ${ }^{160}$ Foi publicado um ensaio de fase 2 com o tofacitinib em pomada com resultados positivos, mas apenas para doença ligeira a moderada. ${ }^{161}$

\subsection{Anti-IL-13 (lebrikizumab / tralokinumab)}

A IL-13 parece desempenhar um papel na fisiopatologia da DA dada a sobre-expressão em pele afectada. ${ }^{131}$ Pode comprometer a integridade da barreira epidérmica pela diminuição da expressão de loricrina e involucrina. ${ }^{162} \mathrm{Um}$ estudo clínico de fase 2 que avaliou a eficácia e segurança de lebrikizumab - um anticorpo monoclonal anti-IL-13 - em 209 doentes com DA moderada a grave, revelou melhorias significativas em vários parâmetros de gravidade. ${ }^{163} \mathrm{O}$ desenho do estudo impôs a associação de dermocorticóides bidiários nos grupos tratamento e placebo o que poderá explicar as altas taxas de resposta ao placebo $(82,4 \%$ vs $62,3 \%, p=0,026$ ); a curta duração do ensaio impediu a determinação da eficácia e segurança a longo prazo.

O tralokinumab é um anticorpo monoclonal humano que também tem como alvo a IL-13. Estudos ainda em curso mostraram alguma melhoria com doses altas, mas a terapia com corticosteróides tópicos no grupo placebo, à semelhança do estudo com lebrikizumab, comprometeu provavelmente também a significância estatística. ${ }^{164}$

Em resumo, o bloqueio específico da IL-13 parece se uma opção promissora, mas a interpretação dos resultados dos ensaios de lebrikizumab e tralokinumab é comprometida pelo uso concomitante de corticoterapia tópica. Desconhece-se se o efeito destes fármacos será semelhante ao bloqueio duplo de IL-4 / IL-13 obtido com o dupilumab.

\subsection{Anti-IL-31 (nemolizumab)}

A IL-31, um produto de células Th2, parece ser uma importante citocina pruritogénica. ${ }^{165}$ Para além disso, amplifica a secreção de citocinas pró-inflamatórias, compromete a 


\section{Educação Médica Contínua}

função da barreira cutânea por alteração da diferenciação terminal epidérmica e dos constituintes lipídicos, e recentemente descobriu-se que ativa cascatas de transdução de sinal, como a via JAK-STAT. ${ }^{166}$

O nemolizumab é um anticorpo monoclonal humanizado contra o receptor A da IL-31. Um estudo clínico de fase 1 mostrou que uma dose única subcutânea resolveu o prurido em doentes adultos com DA moderada a grave. Como consequência, estes doentes tiveram menos distúrbios do sono relacionados com o desconforto da pele e foram capazes de reduzir o uso concomitante de glicocorticóides tópicos. ${ }^{165}$ Mais recentemente, um estudo de fase 2 controlado por placebo, avaliou a eficácia e segurança em 264 pacientes com DA moderada a grave. ${ }^{167} \mathrm{O}$ nemolizumab pareceu funcionar rapidamente, com uma redução de quase $30 \%$ do score de prurido logo à primeira semana, dependente da dose, em comparação com apenas um efeito ligeiro no grupo placebo. Não houve comparações estatísticas para endpoints secundários, embora sejam sugeridas melhorias nos índices de sono (início, duração total e eficiência do sono) e do EASI. No prolongamento deste ensaio até às 64 semanas, assistiu-se reduções do score de prurido entre $73 \%$ e $89,6 \%$ e de EASI entre $68,5 \%$ e $78,9 \%$, de acordo com a dose e posologia. ${ }^{168}$ Embora estes resultados preliminares pareçam promissores, particularmente no prurido, estudos adicionais são necessários para confirmar a eficácia sobre as lesões inflamatórias da pele e a segurança do fármaco.

Tal como com o dupilumab, o facto de alguns doentes que receberam os fármacos activos nos ensaios não terem tido melhoria sintomática sugere que outro mecanismo imunológico possa ser mais relevante na sua doença.

\subsection{Inibidor da IL-33 (ANB020)}

Os resultados preliminares de um estudo de um novo biológico injectável, ANB020 (AnaptysBio), apresentado no Congresso da AAD de 2018, também parece promissor. ${ }^{158}$ O ANB020 é um anticorpo monoclonal humanizado que inibe a IL-33. Quinze dias após uma única injeção, 75\% dos 12 pacientes atingiram o EASI-50, e os efeitos duraram pelo menos até ao dia 57 . No entanto, os resultados deste estudo de fase 2 são muito preliminares.

\subsection{Inibidores da IL-17}

Também no Congresso da AAD de 2018 foi apresentado um ensaio de fase $1 \mathrm{com}$ um anticorpo monoclonal com alta afinidade para a IL-17C (MOR106) no tratamento de DA.158 A IL-17C é uma citocina mais específica para células epiteliais do que IL17A e IL-17F. O agente MOR106 produziu uma resposta EASI-50 às 4 semanas em 5 dos 6 indivíduos estudados na dose de $10 \mathrm{mg} / \mathrm{kg}$, sem efeitos adversos reportados.

Estão em curso 2 ensaios com um inibidor da IL-17A secukinumab - em doentes com DA moderada a grave. Um deles já terminou mas, até à data, não disponibilizou ainda resultados ${ }^{169}$; o outro ainda não iniciou a fase de recrutamento. ${ }^{170}$

\section{CONCLUSÃO}

Nas últimas duas décadas, assistiu-se a um tremendo progresso no tratamento da psoríase moderada a grave. Contudo, numa doença tão prevalente e impactante como a DA, as opções de tratamento permaneceram essencialmente inalteradas no mesmo período. É surpreendente que uma redução na atividade da doença semelhante à redução de PASI 75 da psoríase seja dificilmente alcançada na dermite atópica. Para a doença ligeira a moderada, os agentes tópicos como emolientes reconstituintes de barreira, corticosteróides e inibidores tópicos de calcineurina oferecem um controle seguro e eficaz. No entanto, quando se trata de controlar a DA moderada a grave, permanece um enorme vazio terapêutico. As opções sistémicas actuais são limitadas pela imunossupressão e pelas toxicidades sistémicas cumulativas. Encontrar um agente eficaz e seguro para o tratamento a longo prazo da DA moderada a grave continua a ser uma necessidade premente da nossa prática clínica.

Os avanços mais gratificantes neste propósito resultaram de uma melhor compreensão dos mecanismos imunológicos e inflamatórios da dermatose. $O$ exemplo paradigmático é o desenvolvimento de dupilumab que demonstrou uma redução notável na actividade da doença com relativamente poucos efeitos adversos. Esperemos que os muitos outros novos fármacos em investigação venham juntar-se ao armamentário terapêutico na gestão da DA e venham a constituir uma resposta efectiva para as pessoas que sofrem desta doença grave, comum, debilitante e complexa.

Conflitos de interesse: Os autores declaram não possuir conflitos de interesse.

Suporte financeiro: $O$ presente trabalho não foi suportado por nenhum subsídio ou bolsa.

Conflicts of interest: The authors have no conflicts of interest to declare.

Financing Support: This work has not received any contribution, grant or scholarship.

\section{REFERÊNCIAS}

1. Williams HC. Epidemiology of atopic dermatitis. Clin Exp Dermatol. 2000;25:522-9. doi:10.1046/j.13652230.2000.00698.x.

2. Hanifin JM, Reed ML. A population-based survey of eczema prevalence in the United States. Dermat Contact Atopic Occup Drug. 2007;18:82-91.

3. Carroll CL, Balkrishnan $\mathrm{R}$, Feldman $\mathrm{SR}$, Fleischer ABJ, Manuel JC. The burden of atopic dermatitis: impact on the patient, family, and society. Pediatr Dermatol. 2005;22:192-9. doi:10.1111/i.15251470.2005.22303.x.

4. Kemp AS. Cost of illness of atopic dermatitis in children: a societal perspective. Pharmacoeconomics. 2003;21:105-113. 
5. Lapidus CS, Kerr PE. Social impact of atopic dermatitis. Med Health R I. 2001;84:294-5.

6. Chamlin SL, Frieden IJ, Williams ML, Chren M-M. Effects of atopic dermatitis on young American children and their families. Pediatrics. 2004;114:607-11. doi:10.1542/peds.2004-0374.

7. Fivenson D, Arnold RJG, Kaniecki DJ, Cohen JL, Frech F, Finlay AY. The effect of atopic dermatitis on total burden of illness and quality of life on adults and children in a large managed care organization. J Manag Care Pharm. 2002;8:333-42. doi:10.18553/jmcp.2002.8.5.333.

8. Finlay AY, Khan GK. Dermatology Life Quality Index (DLQI)-a simple practical measure for routine clinical use. Clin Exp Dermatol. 1994;19:210-6.

9. Kiebert G, Sorensen S V, Revicki D, et al. Atopic dermatitis is associated with a decrement in health-related quality of life. Int J Dermatol. 2002;41:151-8.

10. Weidinger $S$, Novak $N$. Atopic dermatitis. Lancet. 2016;387:1109-122. doi:10.1016/S0140-6736(15)00149-X.

11. Kunz B, Oranje AP, Labreze L, Stalder JF, Ring J, Taieb A. Clinical validation and guidelines for the SCORAD index: consensus report of the European Task Force on Atopic Dermatitis. Dermatology. 1997;195:10-9.

12. Schmitt J, Langan S, Deckert $S$, et al. Assessment of clinical signs of atopic dermatitis: a systematic review and recommendation. J Allergy Clin Immunol. 2013;132:1337-47. doi:10.1016/i.jaci.2013.07.008.

13. Chopra R, Silverberg Jl. Assessing the severity of atopic dermatitis in clinical trials and practice. Clin Dermatol. 2018;36:606-15. doi:10.1016/j.clindermatol.2018.05.012.

14. Arkwright PD, Motala C, Subramanian H, Spergel J, Schneider LC, Wollenberg A. Management of difficult-to-treat atopic dermatitis. J Allergy Clin Immunol Pract. 2013;1:142-51. doi:10.1016/i.jaip.2012.09.002.

15. Ring J, Alomar A, Bieber T, et al. Guidelines for treatment of atopic eczema (atopic dermatitis) Part I. J Eur Acad Dermatology Venereol. 2012;26:1045-60. doi: 10.1111/j.1468-3083.2012.04635.x.

16. Ring J, Alomar A, Bieber T, et al. Guidelines for treatment of atopic eczema (atopic dermatitis) Part II. J Eur Acad Dermatology Venereol. 2012;26:1176-93. doi:10.1111/j.1468-3083.2012.04636.x.

17. Baumer JH. Atopic eczema in children, NICE. Arch Dis Child Educ Pract Ed. 2008;93:93-7. doi:10.1136/ adc.2008.139626.

18. Silverberg NB. A practical overview of pediatric atopic dermatitis, part 2: triggers and grading. Cutis. 2016;97:326-9.

19. Kiken DA, Silverberg NB. Atopic dermatitis in children, part 1: epidemiology, clinical features, and complications. Cutis. 2006;78:241-7.

20. Brever K, HAussler S, Kapp A, Werfel T. Staphylococcus aureus: colonizing features and influence of an antibacterial treatment in adults with atopic dermatitis. $\mathrm{Br} \mathrm{J}$
Dermatol. 2002; 147:55-61.

21. Bjerre RD, Bandier J, Skov L, Engstrand L, Johansen JD. The role of the skin microbiome in atopic dermatitis: a systematic review. Br J Dermatol. 2017;177:1272-8. doi:10.1111/bjd.15390.

22. Adachi J, Endo K, Fukuzumi T, Tanigawa N, Aoki T. Increasing incidence of streptococcal impetigo in atopic dermatitis. J Dermatol Sci. 1998;17:45-53.

23. Wollenberg A, Zoch C, Wetzel S, Plewig G, Przybilla B. Predisposing factors and clinical features of eczema herpeticum: a retrospective analysis of 100 cases. J Am Acad Dermatol. 2003;49:198-205.

24. Roul S, Ducombs G, Taieb A. Usefulness of the European standard series for patch testing in children. A 3-year single-centre study of 337 patients. Contact Dermatitis. $1999 ; 40: 232-5$.

25. Brasch J, Geier J. Patch test results in schoolchildren. Results from the Information Network of Departments of Dermatology (IVDK) and the German Contact Dermatitis Research Group (DKG). Contact Dermatitis. 1997;37:286-93.

26. Tada J, Toi Y, Arata J. Atopic dermatitis with severe facial lesions exacerbated by contact dermatitis from topical medicaments. Contact Dermatitis. 1994;31:261-3.

27. Giordano-Labadie F, Rance F, Pellegrin F, Bazex J, Dutau $G$, Schwarze HP. Frequency of contact allergy in children with atopic dermatitis: results of a prospective study of 137 cases. Contact Dermatitis. 1999;40:192-5.

28. Mailhol C, Lauwers-Cances V, Rancé F, Paul C, Giordano-Labadie F. Prevalence and risk factors for allergic contact dermatitis to topical treatment in atopic dermatitis: a study in 641 children. Allergy. 2009;64:801-6. doi:10.1111/j.1398-9995.2008.01890.x.

29. Eichenfield LF, Hanifin JM, Beck LA, et al. Atopic dermatitis and asthma: parallels in the evolution of treatment. Pediatrics. 2003;111:608-16.

30. Naldi L, Parazzini F, Gallus S. Prevalence of atopic dermatitis in Italian schoolchildren: factors affecting its variation. Acta Derm Venereol. 2009;89):122-5. doi:10.2340/00015555-0591.

31. Schafer T. The impact of allergy on atopic eczema from data from epidemiological studies. Curr Opin Allergy Clin Immunol. 2008;8:418-22. doi:10.1097/ $\mathrm{ACl} .0 \mathrm{~b} 013 \mathrm{e} 32830 \mathrm{e} 71 \mathrm{a} 7$.

32. Flohr $\mathrm{C}$, Johansson SGO, Wahlgren C-F, Williams $\mathrm{H}$. How atopic is atopic dermatitis? J Allergy Clin Immunol. 2004;1 14:150-8. doi:10.1016/i.jaci.2004.04.027.

33. Brever $K$, Heratizadeh $A$, Wulf $A$, et al. Late eczematous reactions to food in children with atopic dermatitis. Clin Exp Allergy. 2004;34:817-24. doi:10.1111/i.13652222.2004.1953.x.

34. Boyce JA, Assa'ad A, Burks AW, et al. Guidelines for the diagnosis and management of food allergy in the United States: report of the NIAID-sponsored expert panel. J Allergy Clin Immunol. 2010;126(6 Suppl):S1-58. doi:10.1016/j.jaci.2010.10.007. 
35. Bath-Hextall F, Delamere FM, Williams HC. Dietary exclusions for established atopic eczema. Cochrane Database Syst Rev. 2008;1:CD005203. doi:10.1002/14651858. CD005203.pub2.

36. Tupker RA, De Monchy JG, Coenraads PJ, Homan $A$, van der Meer JB. Induction of atopic dermatitis by inhalation of house dust mite. J Allergy Clin Immunol. 1996;97:1064-70.

37. Nankervis H, Pynn E V, Boyle RJ, Rushton L, Williams HC, Hewson DM, et al. House dust mite reduction and avoidance measures for treating eczema. Cochrane Database Syst Rev. 2015;1:CD008426. doi:10.1002/14651858.CD008426.pub2.

38. Krejci-Manwaring J, Tusa MG, Carroll C, Camacho F, Kaur M, Carr D, et al. Stealth monitoring of adherence to topical medication: Adherence is very poor in children with atopic dermatitis. J Am Acad Dermatol. 2007;56:211-6. doi:10.1016/i.jaad.2006.05.073.

39. Ohya $Y$, Williams H, Steptoe A, Saito H, likura $Y$, Anderson $R$, et al. Psychosocial factors and adherence to treatment advice in childhood atopic dermatitis. J Invest Dermatol. $2001 ; 117): 852-7$. doi:10.1046/i.0022202x.2001.01475.x.

40. Misery L, Ortonne J-P, Cambazard F, Guillet G, Thomas $L$, Lorette $G$, et al. PPAD: a tool for presumption of atopic dermatitis. J Dermatol. 2012;39:151-5. doi:10.1111/ j.1346-8138.2011.01381.x.

41. Hanifin J. Diagnostic features of atopic dermatitis. Acta Dermatovener. 1980;92:44-7.

42. Williams HC, Burney PG, Hay RJ, Archer CB, Shipley MJ, Hunter JJ, et al. The U.K. Working Party's Diagnostic Criteria for Atopic Dermatitis. I. Derivation of a minimum set of discriminators for atopic dermatitis. Br J Dermatol. 1994;131:383-96.

43. Eichenfield LF, Hanifin JM, Luger TA, Stevens SR, Pride $\mathrm{HB}$. Consensus conference on pediatric atopic dermatitis. J Am Acad Dermatol. 2003;49:1088-95. doi:10.1067/ S0190.

44. Meduri NB, Vandergriff $T$, Rasmussen $H$, Jacobe $H$. Phototherapy in the management of atopic dermatitis: a systematic review. Photodermatol Photoimmunol Photomed. 2007;23:106-12. doi:10.1111/ i. 1600-0781.2007.00291.x.

45. Sidbury R, Davis DM, Cohen DE, Cordoro KM, Berger TG, Bergman JN, et al. Guidelines of care for the management of atopic dermatitis: Section 3. Management and treatment with phototherapy and systemic agents. J Am Acad Dermatol. 2014;71:327-49. doi:10.1016/i. jaad.2014.03.030.

46. Reynolds NJ, Franklin V, Gray JC, Diffey BL, Farr PM. Narrow-band ultraviolet $B$ and broad-band ultraviolet $A$ phototherapy in adult atopic eczema: a randomised controlled trial. Lancet. 2001;357:2012-6. doi:10.1016/ S0140-6736(00)05114-X.

47. Fernandez-Guarino $M$, Aboin-Gonzalez S, Barchino L, Velazquez D, Arsuaga C, Lazaro P. Treatment of moderate and severe adult chronic atopic dermatitis with narrow-band UVB and the combination of narrow-band UVB/UVA phototherapy. Dermatol Ther. 2016;29:1923. doi: $10.1111 /$ dth. 12273.

48. Hjerppe M, Hasan T, Saksala I, Reunala T. Narrow-band UVB treatment in atopic dermatitis. Acta Derm Venereol. 2001;81:439-40.

49. Dayal S, Pathak K, Sahu P, Jain VK. Narrowband UV-B phototherapy in childhood atopic dermatitis: efficacy and safety. An Bras Dermatol. 2017;92:801-6. doi:10.1590/abd1806-4841.20175958.

50. Majoie IML, Oldhoff JM, van Weelden $H$, Laaper-Ertmann M, Bousema MT, Sigurdsson V, et al. Narrowband ultraviolet $B$ and medium-dose ultraviolet $A 1$ are equally effective in the treatment of moderate to severe atopic dermatitis. J Am Acad Dermatol. 2009;60:77-84. doi:10.1016/i.jaad.2008.08.048.

51. Gambichler T, Othlinghaus N, Tomi NS, Holland-Letz T, Boms S, Skrygan M,et al. Medium-dose ultraviolet (UV) A1 vs. narrowband UVB phototherapy in atopic eczema: a randomized crossover study. $\mathrm{Br} \mathrm{J}$ Dermatol. 2009;160:652-8. doi:10.1111/i.13652133.2008.08984.x.

52. Garritsen FM, Brouwer MW, Limpens J, Spuls PI. Photo(chemo)therapy in the management of atopic dermatitis: an updated systematic review with implications for practice and research. Br J Dermatol. 2014;170:501 13. doi:10.1111/bjd.12645.

53. Tzaneva S, Kittler H, Holzer G, Reliic D, Weber M, Hönigsmann $\mathrm{H}$, et al. 5-Methoxypsoralen plus ultraviolet (UV) $A$ is superior to medium-dose UVA1 in the treatment of severe atopic dermatitis: a randomized crossover trial. Br J Dermatol. 2010;162:655-60. doi:10.1111/i.13652133.2009.09514.x.

54. Der-Petrossian M, Seeber A, Honigsmann H, Tanew A. Half-side comparison study on the efficacy of 8-methoxypsoralen bath-PUVA versus narrow-band ultraviolet $B$ phototherapy in patients with severe chronic atopic dermatitis. Br J Dermatol. 2000;142:39-43.

55. Stern RS. The risk of melanoma in association with long-term exposure to PUVA. J Am Acad Dermatol. 2001;44:755-61. doi:10.1067/mid.2001.114576.

56. Nijsten TEC, Stern RS. The increased risk of skin cancer is persistent after discontinuation of psoralen + ultraviolet A: a cohort study. J Invest Dermatol. 2003;121:252-8. doi:10.1046/i.1523-1747.2003.12350.x.

57. Patel R V, Clark LN, Lebwohl M, Weinberg JM. Treatments for psoriasis and the risk of malignancy. J Am Acad Dermatol. 2009;60:1001-17. doi:10.1016/j. jaad.2008.12.031.

58. Gambichler T. Management of atopic dermatitis using photo(chemo)therapy. Arch Dermatol Res. 2009;301:197203. doi:10.1007/s00403-008-0923-5.

59. Eichenfield LF, Tom WL, Berger TG, Krol A, Paller AS, Schwarzenberger K, et al. Guidelines of care for the management of atopic dermatitis: section 2. Management 


\section{Educação Médica Contínua}

and treatment of atopic dermatitis with topical therapies. J Am Acad Dermatol. 2014;71:116-32. doi:10.1016/j. jaad.2014.03.023.

60. Devillers AC, Oranje AP. Wet-wrap treatment in children with atopic dermatitis: a practical guideline. Pediatr Dermatol. 2012;29:24-7. doi:10.1111/i.15251470.2011.01691.x.

61. Oranje AP, Devillers ACA, Kunz B, Jones SL, DeRaeve L, Van Gysel D, et al. Treatment of patients with atopic dermatitis using wet-wrap dressings with diluted steroids and/or emollients. An expert panel's opinion and review of the literature. J Eur Acad Dermatol Venereol. 2006;20:1277-6. doi:10.1111/i.14683083.2006.01790.x.

62. Devillers ACA, de Waard-van der Spek FB, Mulder PG, Oranje AP. Treatment of refractory atopic dermatitis using "wet-wrap" dressings and diluted corticosteroids: results of standardized treatment in both children and adults. Dermatology. 2002;204:50-5. doi:10.1159/000051810.

63. Foelster-Holst R, Nagel F, Zoellner P, Spaeth D. Efficacy of crisis intervention treatment with topical corticosteroid prednicarbat with and without partial wet-wrap dressing in atopic dermatitis. Dermatology. 2006;212:66-9. doi: 10.1159/000089025.

64. Xu W, Li Y, Chen Z, Liu T, Wang S, Li L. Wet-wrap therapy with halometasone cream for severe adult atopic dermatitis. Postgrad Med. 2018 (in press). doi:10.1080/00 325481.2018 .1478108$.

65. Gonzalez-Lopez G, Ceballos-Rodriguez RM, Gonzalez-Lopez JJ, Feito Rodriguez M, Herranz-Pinto P. Efficacy and safety of wet wrap therapy for patients with atopic dermatitis: a systematic review and meta-analysis. $\mathrm{Br} \mathrm{J}$ Dermatol. 2017;177:688-95. doi:10.1111/bjd.15165.

66. Amor KT, Ryan C, Menter A. The use of cyclosporine in dermatology: part I. J Am Acad Dermatol. 2010;63:9258. doi:10.1016/i.jaad.2010.02.063.

67. Schmitt J, Schmitt N, Meurer M. Cyclosporin in the treatment of patients with atopic eczema - a systematic review and meta-analysis. J Eur Acad Dermatol Venereol. 2007;21:606-19. doi:10.1111/ j. 1468-3083.2006.02023.x.

68. Harper JI, Berth-Jones J, Camp RD, Dillon MJ, Finlay AY, Holden CA, et al. Cyclosporin for atopic dermatitis in children. Dermatology. 2001;203:3-6. doi:10.1159/000051694.

69. Brazzelli V, Prestinari F, Chiesa MG, Borroni RG, Ardigo $M$, Borroni $G$. Sequential treatment of severe atopic dermatitis with cyclosporin $A$ and low-dose narrow-band UVB phototherapy. Dermatology. 2002;204:252-4. doi:10.1159/000057893.

70. Zonneveld IM, De Rie MA, Beljaards RC, Van Der Rhee HJ, Wuite J, Zeegelaar J, et al. The long-term safety and efficacy of cyclosporin in severe refractory atopic dermatitis: a comparison of two dosage regimens. Br J Dermatol. 1996;135 Suppl:15-20.
71. Berth-Jones J, Graham-Brown RA, Marks R, Camp RD, English JS, Freeman K, et al. Long-term efficacy and safety of cyclosporin in severe adult atopic dermatitis. $\mathrm{Br} \mathrm{J}$ Dermatol. 1997;136:76-81.

72. Harper JI, Ahmed I, Barclay G, Lacour M, Hoeger P, Cork MJ, et al. Cyclosporin for severe childhood atopic dermatitis: short course versus continuous therapy. $\mathrm{Br} \mathrm{J}$ Dermatol. 2000;142:52-8.

73. Haeck IM, Knol MJ, Ten Berge O, van Velsen SGA, de Bruin-Weller MS, Bruijnzeel-Koomen CAFM. Enteric-coated mycophenolate sodium versus cyclosporin A as long-term treatment in adult patients with severe atopic dermatitis: a randomized controlled trial. J Am Acad Dermatol. 2011;64:1074-84. doi:10.1016/j. jaad.2010.04.027.

74. Granlund $H$, Erkko P, Remitz A, Langeland T, Helsing P, Nuutinen $M$,et al. Comparison of cyclosporin and UVAB phototherapy for intermittent one-year treatment of atopic dermatitis. Acta Derm Venereol. 2001;81:22-7.

75. Kim C-H, Cheong KA, Park CD, Lee A-Y. Glucosamine improved atopic dermatitis-like skin lesions in $\mathrm{NC}$ / Nga mice by inhibition of Th2 cell development. Scand J Immunol. 2011;73:536-45. doi:10.1111/i.13653083.2011.02526.x.

76. Kwon H-B, Ahn B-J, Choi Y, Jin SY, Cheong KA, Lee J, et al. Combination of glucosamine improved therapeutic effect of low-dose cyclosporin A in patients with atopic dermatitis: a pilot study. J Dermatol. 2013;40:207-10. doi:10.1111/1346-8138.12003.

77. Jin S-Y, Lim W-S, Sung NH, Cheong KA, Lee A-Y. Combination of glucosamine and low-dose cyclosporine for atopic dermatitis treatment: a randomized, placebo-controlled, double-blind, parallel clinical trial. Dermatol Ther. 2015;28:44-51. doi:10.1111/dth.12163.

78. Goujon C, Viguier M, Staumont-Salle D, Bernier C, Guillet $G$, Lahfa $M$, et al. Methotrexate versus cyclosporine in adults with moderate-to-severe atopic dermatitis: a phase III randomized noninferiority trial. J allergy Clin Immunol Pract. 2018; 6:562-9.e3. doi:10.1016/j. jaip.2017.07.007.

79. Law Ping Man S, Bouzille G, Beneton N, Safa G, Dupuy A, Droitcourt C. Drug survival and postdrug survival of first-line immunosuppressive treatments for atopic dermatitis: comparison between methotrexate and cyclosporine. J Eur Acad Dermatol Venereol. 2018 (in press). doi: $10.1111 /$ jdv. 14880.

80. Flohr C, Irvine AD. Systemic therapies for severe atopic dermatitis in children and adults. J Allergy Clin Immunol. 2013;132:774-4.e6. doi:10.1016/i.jaci.2013.03.016.

81. Holme SA, Duley JA, Sanderson J, Routledge PA, Anstey AV. Erythrocyte thiopurine methyl transferase assessment prior to azathioprine use in the UK. QJM. 2002;95:43944.

82. Schram ME, Borgonjen RJ, Bik CMJM, van der Schroeff JG, van Everdingen JJE, Spuls PI. Off-label use of azathioprine in dermatology: a systematic review. Arch 
Dermatol. $2011 ; 147: 474-88$. doi:10.1001/archdermatol.2011.79.

83. Berth-Jones J, Takwale A, Tan E, Barclay G, Agarwal S, Ahmed I, et al. Azathioprine in severe adult atopic dermatitis: a double-blind, placebo-controlled, crossover trial. Br J Dermatol. 2002;147:324-30.

84. Meggitt SJ, Gray JC, Reynolds NJ. Azathioprine dosed by thiopurine methyltransferase activity for moderate-to-severe atopic eczema: a double-blind, randomised controlled trial. Lancet. 2006;367:839-46. doi:10.1016/ S0140-6736(06)68340-2.

85. Schram ME, Roekevisch E, Leeflang MM, Bos JD, Schmitt J, Spuls PI. A randomized trial of methotrexate versus azathioprine for severe atopic eczema. J Allergy Clin Immunol. 2011 ; 128:353-9. doi:10.1016/j. jaci.201 1.03.024.

86. Gerbens LA, Hamann SA, Brouwer MW, Roekevisch E, Leeflang MM, Spuls PI. Methotrexate and azathioprine in severe atopic dermatitis: a 5-year follow up study of a randomised controlled trial. Br J Dermatol. 2018; 178:1288-96. doi:10.1111/bjd.16240.

87. Fuggle NR, Bragoli W, Mahto A, Glover M, Martinez AE, Kinsler VA. The adverse effect profile of oral azathioprine in pediatric atopic dermatitis, and recommendations for monitoring. J Am Acad Dermatol. 2015;72:108-14. doi:10.1016/i.jaad.2014.08.048.

88. Orvis AK, Wesson SK, Breza TSJ, Church AA, Mitchell $\mathrm{CL}$, Watkins SW. Mycophenolate mofetil in dermatology. J Am Acad Dermatol. 2009;60:182-3. doi:10.1016/j. jaad.2008.08.049.

89. Salvadori $M$, Bertoni $E$, Budde $K$, Holzer $H$, Civati $G$, Lien B, et al. Superior efficacy of enteric-coated mycophenolate vs mycophenolate mofetil in de novo transplant recipients: pooled analysis. Transplant Proc. 2010;42:1325-8. doi:10.1016/j.transproceed.2010.03.044.

90. Murray ML, Cohen JB. Mycophenolate mofetil therapy for moderate to severe atopic dermatitis. Clin Exp Dermatol. 2007;32:23-7. doi:10.1111/i.13652230.2006.02290.x.

91. Garritsen FM, Roekevisch E, van der Schaft J, Deinum J, Spuls Pl, de Bruin-Weller MS. Ten years experience with oral immunosuppressive treatment in adult patients with atopic dermatitis in two academic centres. J Eur Acad Dermatol Venereol. 2015;29:1905-12. doi:10.1111/ idv. 13064.

92. Bangert CA, Costner MI. Methotrexate in dermatology. Dermatol Ther. 2007;20:216-28. doi:10.1111/j.15298019.2007.00135.x.

93. Dogra S, Mahajan R. Systemic methotrexate therapy for psoriasis: past, present and future. Clin Exp Dermatol. 2013;38:573-88. doi:10.1111/ced.12062.

94. El-Khalawany MA, Hassan H, Shaaban D, Ghonaim N, Eassa B. Methotrexate versus cyclosporine in the treatment of severe atopic dermatitis in children: a multicenter experience from Egypt. Eur J Pediatr. 2013;172:351-6. doi:10.1007/s00431-012-1893-3.

95. Weatherhead SC, Wahie S, Reynolds NJ, Meggitt SJ. An open-label, dose-ranging study of methotrexate for moderate-to-severe adult atopic eczema. $\mathrm{Br} \mathrm{J}$ Dermatol. 2007;156:346-51. doi:10.1111/j.13652133.2006.07686.x.

96. Lyakhovitsky A, Barzilai A, Heyman R, Baum S, Amichai $B$, Solomon $M$, et al. Low-dose methotrexate treatment for moderate-to-severe atopic dermatitis in adults. J Eur Acad Dermatol Venereol. 2010;24:43-9. doi:10.1111/ j.1468-3083.2009.03351.x.

97. Goujon C, Berard F, Dahel K, Guillot I, Hennino A, Nosbaum $A$, et al. Methotrexate for the treatment of adult atopic dermatitis. Eur J Dermatol. 2006;16:155-8.

98. Heddle RJ, Soothill JF, Bulpitt CJ, Atherton DJ. Combined oral and nasal beclomethasone diproprionate in children with atopic eczema: a randomised controlled trial. Br Med J. 1984;289:651-4.

99. Galli E, Chini L, Moschese V, Paone F, Menichelli A, Fraioli $G$, et al. Methylprednisolone bolus: a novel therapy for severe atopic dermatitis. Acta Paediatr. 1994;83:315-7.

100. Schmitt J, Schakel K, Folster-Holst R, Baver A, Oertel $R$, Augustin $M$, et al. Prednisolone vs. ciclosporin for severe adult eczema. An investigator-initiated double-blind placebo-controlled multicentre trial. $\mathrm{Br}$ J Dermatol. 2010;162:661-8. doi:10.1111/i.13652133.2009.09561.x.

101. Schadt CR, Jackson SM. Glucocorticoids. In: Bolognia JL, Schaffer J V, Cerroni L, editors. Dermatology. 4th Ed. Amsterdam: Elsevier; 2018:2186-99.

102. Akdis CA, Akdis $M$, Bieber $T$, Boguniewicz M, Eigenmann $P$, Hamid $Q$, et al. Diagnosis and treatment of atopic dermatitis in children and adults: European Academy of Allergology and Clinical Immunology/American Academy of Allergy, Asthma and Immunology/ PRACTALL Consensus Report. Allergy. 2006;61:969-87. doi:10.1111/j.1398-9995.2006.01153.x.

103. Drucker AM, Eyerich K, de Bruin-Weller MS, Thyssen JP, Spuls PI, Irvine AD, et al. Use of systemic corticosteroids for atopic dermatitis: International Eczema Council consensus statement. Br J Dermatol. 2018; 178:768-75. doi: $10.1111 /$ bjd. 15928.

104. Hanifin JM, Chan SC. Monocyte phosphodiesterase abnormalities and dysregulation of lymphocyte function in atopic dermatitis. J Invest Dermatol. 1995;105(1 Suppl):84S-88S.

105. Samrao A, Berry TM, Goreshi R, Simpson EL. A pilot study of an oral phosphodiesterase inhibitor (apremilast) for atopic dermatitis in adults. Arch Dermatol. 2012;148:890-7. doi:10.1001/archdermatol.2012.812.

106. Volf EM, Au SC, Dumont N, Scheinman P, Gottlieb AB. A phase 2, open-label, investigator-initiated study to evaluate the safety and efficacy of apremilast in subjects with recalcitrant allergic contact or atopic dermatitis. J Drugs Dermatol. 2012;11:341-6. 
107. Abrouk M, Farahnik B, Zhu TH, Nakamura M, Singh $\mathrm{R}$, Lee $\mathrm{K}$, et al. Apremilast treatment of atopic dermatitis and other chronic eczematous dermatoses. J Am Acad Dermatol. 2017;77:177-80. doi:10.1016/j. jaad.2017.03.020.

108. Saporito RC, Cohen DJ. Apremilast use for moderate-to-severe atopic dermatitis in pediatric patients. Case Rep Dermatol. 2016;8:179-84. doi:10.1159/000446836.

109. Farahnik B, Beroukhim K, Nakamura M, Abrouk M, Zhu $\mathrm{TH}$, Singh R, et al. Use of an oral phosphodiesterase-4 inhibitor (apremilast) for the treatment of chronic, severe atopic dermatitis: a case report. Dermatol Online J. $2017 ; 23$.

110. Simon D, Hosli S, Kostylina G, Yawalkar N, Simon HU. Anti-CD20 (rituximab) treatment improves atopic eczema. J Allergy Clin Immunol. 2008;121:122-8. doi:10.1016/i.jaci.2007.11.016.

111. Ponte $P$, Lopes MJ. Apparent safe use of single dose rituximab for recalcitrant atopic dermatitis in the first trimester of a twin pregnancy. J Am Acad Dermatol. 2010;63:355-6. doi:10.1016/i.jaad.2009.05.015.

112. Sedivá $A$, Kayserová J, Vernerová E, Poloucková A, Capková S, Spísek R, et al. Anti-CD20 (rituximab) treatment for atopic eczema. J Allergy Clin Immunol. 2008; 121 :1515-7. doi:10.1016/i.jaci.2008.03.007.

113. McDonald BS, Jones J, Rustin M. Rituximab as a treatment for severe atopic eczema: failure to improve in three consecutive patients. Clin Exp Dermatol. 2016;41:45-7. doi: 10.1111 /ced. 12691.

114. Simon D, Wittwer J, Kostylina G, Buettiker U, Simon HU, Yawalkar N. Alefacept (lymphocyte function-associated molecule $3 / \lg$ G fusion protein) treatment for atopic eczema. J Allergy Clin Immunol. 2008;122:423-4. doi:10.1016/i.jaci.2008.06.010.

115. Moul DK, Routhouska SB, Robinson MR, Korman NJ. Alefacept for moderate to severe atopic dermatitis: a pilot study in adults. J Am Acad Dermatol. 2008;58:984-9. doi:10.1016/i.jaad.2008.02.007.

116. Jacobi A, Antoni C, Manger B, Schuler G, Hertl M. Infliximab in the treatment of moderate to severe atopic dermatitis. J Am Acad Dermatol. 2005;52:522-6. doi:10.1016/i.jaad.2004.11.022.

117. Vestergaard C, Deleuran M, Kragballe K. Two cases of atopic dermatitis-like conditions induced in psoriasis patients treated with infliximab. J Eur Acad Dermatol Venereol. 2007;21:1272-4. doi:10.1111/ j.1468-3083.2007.02165.x.

118. Ruiz-Villaverde R, Galan-Gutierrez M. Exacerbation of atopic dermatitis in a patient treated with infliximab. Actas Dermosifiliogr. 2012;103:743-6. doi:10.1016/j. ad.2011.11.013.

119. Wright RC. Atopic dermatitis-like eruption precipitated by infliximab. J Am Acad Dermatol. 2003;49:160-1. doi: 10.1067/mid.2003.252.

120. Fernandez-Anton Martinez MC, Leis-Dosil V, Alfageme-Roldan F, Paravisini A, Sanchez-Ramon S, Suarez
Fernandez R. Omalizumab for the treatment of atopic dermatitis. Actas Dermosifiliogr. 2012;103:624-8. doi:10.1016/j.ad.2011.07.013.

121. Forman SB, Garrett AB. Success of omalizumab as monotherapy in adult atopic dermatitis: case report and discussion of the high-affinity immunoglobulin $E$ receptor, FcepsilonRI. Cutis. 2007;80:38-40.

122. Vigo PG, Girgis KR, Pfuetze BL, Critchlow ME, Fisher J, Hussain I. Efficacy of anti-IgE therapy in patients with atopic dermatitis. J Am Acad Dermatol. 2006;55:168170. doi:10.1016/i.jaad.2005.12.045.

123. Garmhausen D, Hagemann T, Bieber T, Dimitriou I, Fimmers R, Diepgen T,et al. Characterization of different courses of atopic dermatitis in adolescent and adult patients. Allergy. 2013;68:498-506. doi:10.1111/ all. 12112 .

124. Kim DH, Park KY, Kim BJ, Kim MN, Mun SK. Anti-immunoglobulin $E$ in the treatment of refractory atopic dermatitis. Clin Exp Dermatol. 2013;38:496-500. doi:10.1111/j.1365-2230.2012.04438.x.

125. Belloni B, Ziai M, Lim A, Lemercier B, Sbornik M, Weidinger $S$, et al. Low-dose anti-lgE therapy in patients with atopic eczema with high serum IgE levels. J Allergy Clin Immunol. 2007;120:1223-5. doi:10.1016/j. jaci.2007.08.060.

126. Hotze $M$, Baurecht $H$, Rodriguez $E$, Chapman-Rothe $N$, Ollert $M$, Fölster-Holst R, et al. Increased efficacy of omalizumab in atopic dermatitis patients with wild-type filaggrin status and higher serum levels of phosphatidylcholines. Allergy. 2014;69:132-5. doi:10.1111/ all. 12234 .

127. Sheinkopf LE, Rafi AW, Do LT, Katz RM, Klaustermeyer WB. Efficacy of omalizumab in the treatment of atopic dermatitis: a pilot study. Allergy asthma Proc. 2008;29:530-7. doi:10.2500/aap.2008.29.3160.

128. Velling P, Skowasch D, Pabst S, Jansen E, Tuleta I, Grohe C. Improvement of quality of life in patients with concomitant allergic asthma and atopic dermatitis: one year follow-up of omalizumab therapy. Eur J Med Res. $2011 ; 16: 407-10$.

129. Heil PM, Maurer D, Klein B, Hultsch T, Stingl G. Omalizumab therapy in atopic dermatitis: depletion of $\lg E$ does not improve the clinical course - a randomized, placebo-controlled and double blind pilot study. J Dtsch Dermatol Ges. 2010;8:990-8. doi:10.1111/i.16100387.2010.07497.x.

130. Oldhoff JM, Darsow U, Werfel T, Katzer K, Wulf A, Laifaoui J,et al. Anti-IL-5 recombinant humanized monoclonal antibody (mepolizumab) for the treatment of atopic dermatitis. Allergy. 2005;60:693-6. doi:10.1111/j.13989995.2005.00791.x.

131. Guttman-Yassky E, Nograles KE, Krueger JG. Contrasting pathogenesis of atopic dermatitis and psoriasis--part I: clinical and pathologic concepts. J Allergy Clin Immunol. $2011 ; 127: 1110-8$. doi:10.1016/i.jaci.2011.01.053.

132. Boguniewicz M, Leung DY. Atopic dermatitis: a disease 
of altered skin barrier and immune dysregulation. Immunol Rev. 2011;242:233-246. doi:10.1111/j.1600065X.2011.01027.x.

133. Borges AS, Pinheiro R, Brasileiro A. Dermite atópica : os novos conhecimentos sobre a fisiopatologia da doença. Rev Soc Port Dermatol Venereol. 2017;75:117-122.

134. Shirley M. Dupilumab: First Global Approval. Drugs. 2017;77:1115-21. doi:10.1007/s40265-017-0768-3.

135. Beck LA, Thaci D, Hamilton JD, Graham NM, Bieber $\mathrm{T}$, Rocklin $\mathrm{R}$, et al. Dupilumab treatment in adults with moderate-to-severe atopic dermatitis. $N$ Engl J Med. 2014;371:130-9. doi:10.1056/NEJMoa1314768.

136. Simpson EL, Gadkari A, Worm M, Soong W, Blauvelt A, Eckert $L$, et al. Dupilumab therapy provides clinically meaningful improvement in patient-reported outcomes (PROs): A phase Ilb, randomized, placebo-controlled, clinical trial in adult patients with moderate to severe atopic dermatitis (AD). J Am Acad Dermatol. 2016;75:50615. doi:10.1016/i.jaad.2016.04.054.

137. Hamilton JD, Suarez-Farinas M, Dhingra N, Cardinale I, Li X, Kostic A, et al. Dupilumab improves the molecular signature in skin of patients with moderate-to-severe atopic dermatitis. J Allergy Clin Immunol. 2014;134:12931300. doi:10.1016/i.jaci.2014.10.013.

138. Simpson EL, Bieber T, Guttman-Yassky E, Beck LA, Blauvelt $A$, Cork MJ,et al. Two phase 3 trials of dupilumab versus placebo in atopic dermatitis. $N$ Engl J Med. 2016;375:2335-48. doi:10.1056/NEJMoa1610020.

139. Blauvelt A, de Bruin-Weller M, Gooderham M, Cather JC, Weisman J, Pariser D, et al. Long-term management of moderate-to-severe atopic dermatitis with dupilumab and concomitant topical corticosteroids (LIBERTY AD CHRONOS): a 1 -year, randomised, double-blinded, placebo-controlled, phase 3 trial. Lancet. 2017;389:2287303. doi:10.1016/S0140-6736(17)31191-1.

140. Sanofi, Regeneron Pharmaceuticals. Study to Assess the Long-term Safety of Dupilumab Administered in Participants $\geq 6$ Months to $<18$ Years of Age With Atopic Dermatitis (AD). NCT02612454@ clinicaltrials.gov. [Accessed September 26, 2018]Available from:https:// clinicaltrials.gov/ct2/show/NCT02612454. 2018.

141. Sanofi, Regeneron Pharmaceuticals. Efficacy and Safety of Dupilumab in Patients $\geq 12$ to $<18$ Years of Age, With Moderate-to-Severe Atopic Dermatitis. NCT03054428 @ clinicaltrials.gov. [Accessed September 26, 2018] Available from:https://clinicaltrials.gov/ct2/show/record/NCT03054428. 2018.

142. Sanofi, Regeneron Pharmaceuticals. Study to Investigate the Efficacy and Safety of Dupilumab Administered With Topical Corticosteroids (TCS) in Participants $\geq 6$ to $<12$ Years With Severe Atopic Dermatitis (AD). NCT03345914 @ clinicaltrials.gov. [Accessed September 26, 2018]Available from:https://clinicaltrials.gov/ ct2/show/record/NCT03345914. 2018.

143. Sanofi, Regeneron Pharmaceuticals. Safety, Pharmacokinetics and Efficacy of Dupilumab in Patients $\geq 6$ Months to $<6$ Years With Severe Atopic Dermatitis (Liberty AD PRESCHOOL). NCT03346434 @ clinicaltrials.gov. [Accessed September 26, 2018]Available from:https://clinicaltrials.gov/ct2/show/NCT03346434. 2018.

144. Simpson E. Dupilumab Efficacy and Safety in Adolescents with Moderate-to-Severe Atopic Dermatitis: Results from a Multicenter, Randomized, Placebo-Controlled, Double-Blind, Parallel-Group, Phase 3 Study. In: 27th European Academy of Dermatology and Venereology (EADV) Congress. Paris; 2018:Abstract D3T01.1L. Presented September 15, 2018.

145. Jolles S. A review of high-dose intravenous immunoglobulin treatment for atopic dermatitis. Clin Exp Dermatol. 2002;27:3-7.

146. Bemanian MH, Movahedi M, Farhoudi A, Gharagozlou $M$, Seraj $M H$, Pourpak $Z$, et al. High doses intravenous immunoglobulin versus oral cyclosporine in the treatment of severe atopic dermatitis. Iran J Allergy Asthma Immunol. 2005;4:139-43. doi:04.03/ijaai.139143.

147. Gorgun G, Miller KB, Foss FM. Immunologic mechanisms of extracorporeal photochemotherapy in chronic graft-versus-host disease. Blood. 2002;100:941-7. doi:10.1182/blood-2002-01-0068.

148. Chiricozzi A, Faleri S, Lanti A, Adorno G, Lorè B, Chimenti $S$, et al. Apheresis in the treatment of recalcitrant atopic dermatitis: case series and review of the literature. Eur J Dermatol. 2014;24:545-50. doi:10.1684/ ejd.2014.2383.

149. Radenhausen M, Michelsen S, Plewig G, Bechara FG, Altmeyer P, Hoffmann K. Bicentre experience in the treatment of severe generalised atopic dermatitis with extracorporeal photochemotherapy. J Dermatol. $2004 ; 31: 961-70$.

150. Koppelhus U, Poulsen J, Grunnet N, Deleuran MS, Obitz E. Cyclosporine and extracorporeal photopheresis are equipotent in treating severe atopic dermatitis: a randomized cross-over study comparing two efficient treatment modalities. Front Med. 2014;1:33. doi:10.3389/ fmed.2014.00033.

151. Akdis CA. Therapies for allergic inflammation: refining strategies to induce tolerance. Nat Med. 2012;18:73649. doi:10.1038/nm.2754.

152. Compalati E, Rogkakou A, Passalacqua G, Canonica GW. Evidences of efficacy of allergen immunotherapy in atopic dermatitis: an updated review. Curr Opin Allergy Clin Immunol. 2012;12:427-33. doi:10.1097/ ACl.0b013e328354e540.

153. Darsow U, Forer I, Ring J. Allergen-specific immunotherapy in atopic eczema. Curr Allergy Asthma Rep. $2011 ; 11: 277-83$. doi:10.1007/s 1 1882-011-0194-7.

154. Tam H, Calderon MA, Manikam L, Nankervis H, García Núñez I, Williams $H C$, et al. Specific allergen immunotherapy for the treatment of atopic eczema. Cochrane Database Syst Rev. 2016;2:CD008774. doi:10.1002/14651858.CD008774.pub2.

155. Wegner J, Weinmann-Menke J, von Stebut E. 


\section{Educação Médica Contínua}

Immunoadsorption for treatment of severe atopic dermatitis. Atheroscler Suppl. 2017;30:264-70. doi:10.1016/j. atherosclerosissup.2017.05.043.

156. Cotter DG, Schairer D, Eichenfield L. Emerging therapies for atopic dermatitis: JAK inhibitors. J Am Acad Dermatol. 2018;78:S53-S62. doi:10.1016/j.jaad.2017.12.019.

157. Guttman-Yassky E, Silverberg JI, Nemoto O, Forman SB, Wilke A, Prescilla $R$, et al. Baricitinib in adult patients with moderate-to-severe atopic dermatitis: a phase 2 parallel, double-blinded, randomized placebo-controlled multiple-dose study. J Am Acad Dermatol. 2018. doi:10.1016/i.jaad.2018.01.018.

158. Fraser KA. American Academy of Dermatology Annual Meeting: San Diego, CA, USA, 16-20 Feb 2018. Am J Clin Dermatol. 2018;19:287-90. doi:10.1007/s40257018-0351-z.

159. Damsky W, King BA. JAK inhibitors in dermatology: The promise of a new drug class. J Am Acad Dermatol. 2017;76:736-44. doi:10.1016/i.jaad.2016.12.005.

160. Levy LL, Urban J, King BA. Treatment of recalcitrant atopic dermatitis with the oral Janus kinase inhibitor tofacitinib citrate. J Am Acad Dermatol. 2015;73:395-9. doi:10.1016/i.jaad.2015.06.045.

161. Bissonnette R, Papp KA, Poulin Y, Gooderham M, Raman $M$, Mallbris $L$, et al. Topical tofacitinib for atopic dermatitis: a phase lla randomized trial. $\mathrm{Br} J$ Dermatol. 2016;175:902-911. doi:10.1111/bjd.14871.

162. Kim BE, Leung DYM, Boguniewicz M, Howell MD. Loricrin and involucrin expression is down-regulated by Th2 cytokines through STAT-6. Clin Immunol. 2008; 126:3327. doi:10.1016/i.clim.2007.11.006.

163. Simpson EL, Flohr C, Eichenfield LF, Bieber T, Sofen $H$, Taïeb $A$, et al. Efficacy and safety of lebrikizumab (an anti-IL-13 monoclonal antibody) in adults with moderate-to-severe atopic dermatitis inadequately controlled by topical corticosteroids: A randomized, placebo-controlled phase II trial (TREBLE). J Am Acad Dermatol. 2018;78:863-871.e11. doi:10.1016/j. jaad.2018.01.017.
164. Andreas Wollenberg, Michael D. Howell, Emma Guttman-Yassky, Jonathan I. Silverberg, Claire Birrell, Chris Kell, Michelle Dawson R van der M. A phase $2 b$ dose-ranging efficacy and safety study of tralokinumab in adult patients with moderate to severe atopic dermatitis (AD). J Am Acad Dermatol. 2017;76(6):AB20. doi:10.1016/i.jaad.2017.04.099.

165. Nemoto O, Furue $M$, Nakagawa $H$, Shiramoto $M$, Hanada $R$, Matsuki $S$, et al. The first trial of CIM331, a humanized antihuman interleukin-31 receptor $A$ antibody, in healthy volunteers and patients with atopic dermatitis to evaluate safety, tolerability and pharmacokinetics of a single dose in a randomized, double-blind, placebo-co. Br J Dermatol. 2016;174:296-304. doi:10.1111/ bid. 14207.

166. Cornelissen C, Marquardt Y, Czaja K, Wenzel J, Frank J, Lüscher-Firzlaff J, et al. IL-31 regulates differentiation and filaggrin expression in human organotypic skin models. J Allergy Clin Immunol. 2012;129:426-33, 433-8. doi:10.1016/i.jaci.2011.10.042.

167. Ruzicka T, Hanifin JM, Furue M, Pulka G, Mlynarczyk I, Wollenberg $A$, et al. Anti-Interleukin-31 receptor $A$ antibody for atopic dermatitis. N Engl J Med. 2017;376:826835. doi:10.1056/NEJMoa 1606490.

168. Kabashima K, Furue M, Hanifin JM, Pulka G, Wollenberg A, Galus R, et al. Nemolizumab in patients with moderate-to-severe atopic dermatitis: Randomized, phase II, long-term extension study. J Allergy Clin Immunol. 2018 (in press). doi:10.1016/i.jaci.2018.03.018.

169. Novartis, Icahn School of Medicine at Mount Sinai. Secukinumab for Treatment of Atopic Dermatitis. NCT02594098@ @ clinicaltrials.gov. [Accessed September 26, 2018]Available from:https://clinicaltrials.gov/ ct2/show/NCT02594098. P2018.

170. Novartis, GWT-TUD GmbH. Investigation of Efficacy of Secukinumab in Patients With Moderate to Serve Atopic Dermatitis (Secu_in_AD). NCT03568136@ clinicaltrials.gov. [Accessed September 26, 2018]Available from:https:// clinicaltrials.gov/ct2/show/NCT03568136. 2018. 


\section{Educação Médica Contínua}

\section{VERIFIQUE O QUE APRENDEU}

1. Acerca da fototerapia no tratamento da DA moderada a grave, indique a falsa:

a) Em ensaios duplamente cegos entre UVAl e nbUVB, a eficácia e a tolerância das duas modalidades foi comparável.

b) Os ensaios disponíveis mostram claramente que a preferência deverá ser dada a UVA1 para agudizações da doença, e a nbUVB para a doença refractária crónica.

c) A principal limitação desta modalidade de fototerapia prende-se com a baixa disponibilidade nos diferentes centros especializados.

d) Doses médias $\left(50 \mathrm{~J} / \mathrm{cm}^{2}\right)$ e altas $\left(130 \mathrm{~J} / \mathrm{cm}^{2}\right)$ de UVA1 são igualmente eficazes.

2. Indique a afirmação verdadeira no tratamento da DA moderada a grave:

a) A CsA demonstrou ser tão eficaz quanto o MMF.

b) $\mathrm{A} C s \mathrm{~A}$ tem um perfil de segurança semelhante ao MTX.

c) nbUVB é mais eficaz do que a CsA.

d) CsA permite intervalos livres de doença após interrupção superiores aos do MTX.

\section{Indique a afirmação falsa no tratamento da} DA moderada a grave:

a) A melhoria dos sintomas nos respondedores ao MTX pode ser observada entre as 2 semanas e os 3 meses.

b) Doentes que não respondam a $15 \mathrm{mg}$ de MTX por semana aos 3 meses, provavelmente não melhorarão com o aumento da dose.

c) A dose inicial de AZA deverá ser reduzida em doentes com níveis indetectáveis de TPMT.

d) O rebound é comum após suspensão de corticosteróides sistémicos.
4. Sobre os ensaios de fase 3 do dupilumab na DA moderada a grave, indique a afirmação falsa:

a) 36 a $38 \%$ dos doentes atingiram IGA 0 ou 1 contra $8 \%$ dos doentes em placebo.

b) Verificou-se uma redução substancial do prurido e uma melhoria dos sintomas de ansiedade e depressão, da qualidade do sono e da qualidade de vida global.

c) Conjuntivite e infecções do tracto respiratório superior ocorreram mais frequentemente em doentes a fazer dupilumab do que a fazer placebo.

d) Os efeitos adversos graves foram superiores no grupo dupilumab.

5. Qual dos seguintes descreve melhor o mecanismo de ação do agente em investigação indicado para o tratamento da DA?

a) Tofacitinib inibe a IL-31.

b) Dupilumab bloqueia o receptor de IL-5.

c) Nemolizumab bloqueia a fosfodiesterase-4 (PDE4).

d) Tralokinumab inibe a IL-13.

6. São terapêuticas ineficazes para a DA, excepto uma:

a) Compressas humedecidas (wet-wrap therapy).

b) Rituximab.

c) Infliximab.

d) Omalizumab.

e) Imunoterapia específica. 